
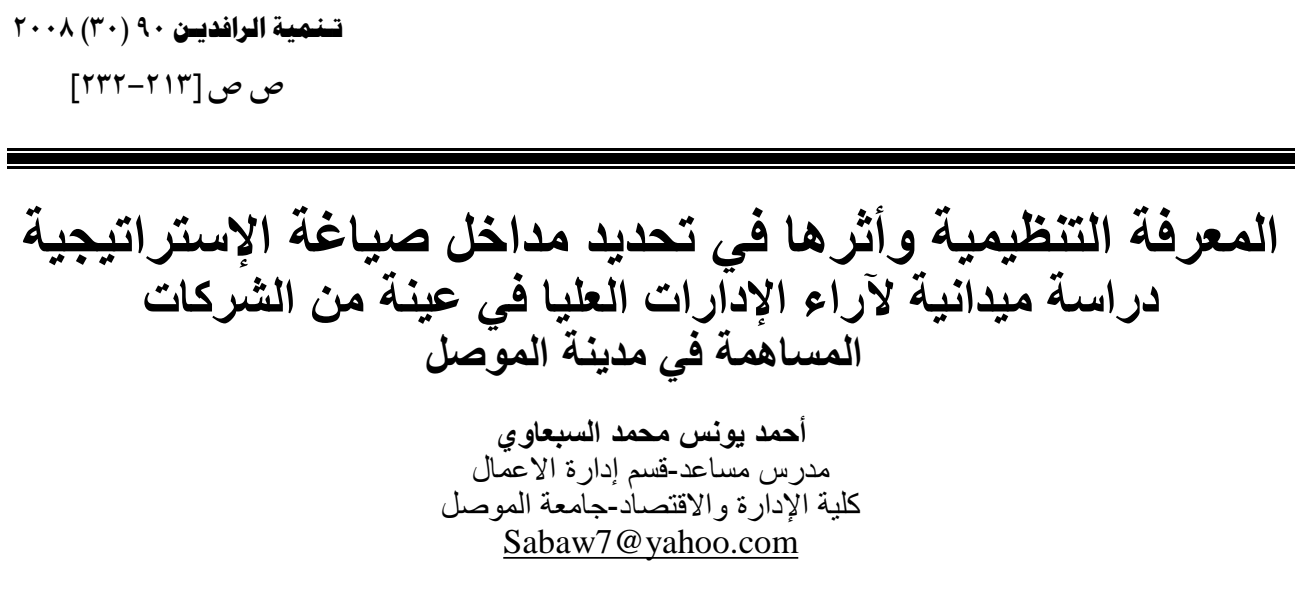

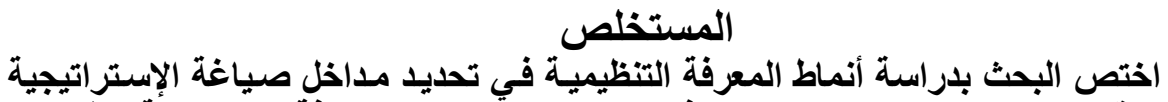

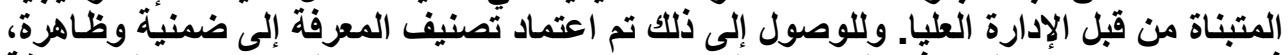

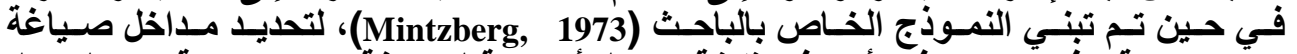

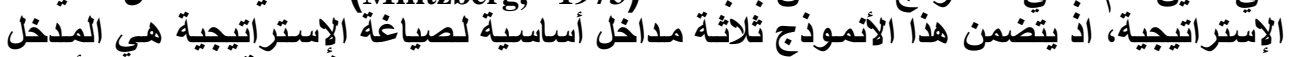

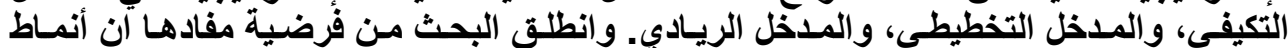

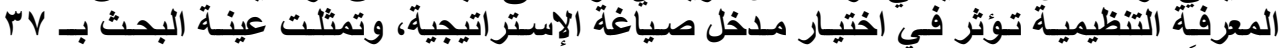

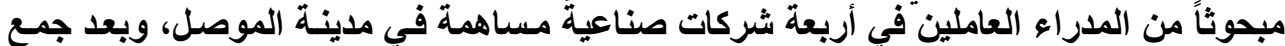

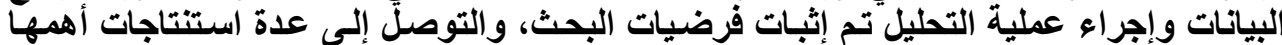
وجود العلاقة التأثيريةة لأنماط المعرفة التنظيمية في مداخل صياغة الإستراتيجة التيجية.

\title{
The Organizational Knowledge and the Effect on Determining the Strategic Formulation Approaches \\ "A Field Study on Top Management Opinions in a Sample of Joint Stock Companies in Mosul City"
}

\author{
Ahmed Y. Saba'wi \\ Assistant Lecturer \\ Department of Business Administration Management \\ University of Mosul
}

\begin{abstract}
The present paper concerned with studying the organizational knowledge manners to determine the approaches of strategies adopted by the top management. In order to reach this result, knowledge has been classified into tact and explicit. A model has been also adopted (Mintzberg 1973) to identify the domains of strategic formulization. The model adopted three basic approaches; they are adaptive approaches, planning approaches and entrepreneurial approaches. The study hypothesized that the manners of organizational knowledge may affect the selection of the approaches of strategic formulization. The sample included (37) working managers in (4) joint stock industrial companies in Mosul City. The data collected and analyzed to show the results. The study concluded several
\end{abstract}

$$
\text { تاريخ قبول النشر V/V/T }
$$

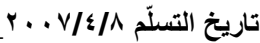




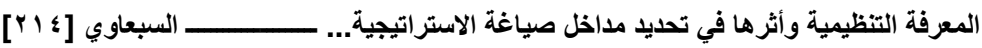

results that prove the effective relationship to the manners of organizational knowledge in the approaches of strategic formulization.

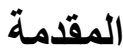

مثلت المعرفة التنظيمية توجهاً إدارياً معاصر اً، انبثق عن التغيرات المتسار عة التها

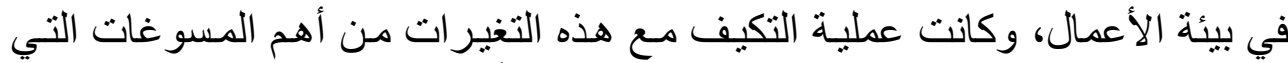

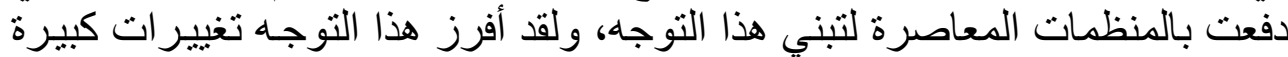

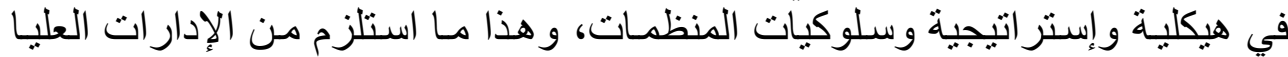

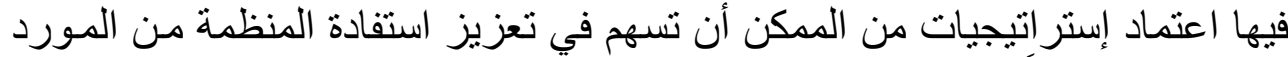

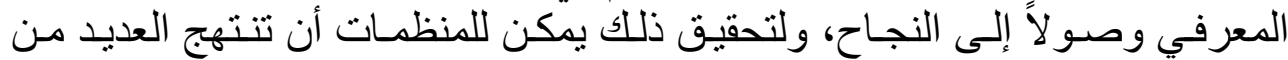

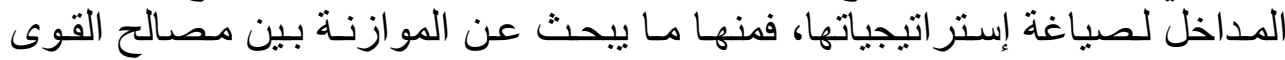

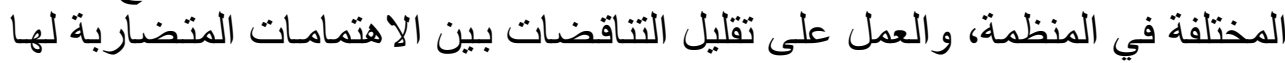

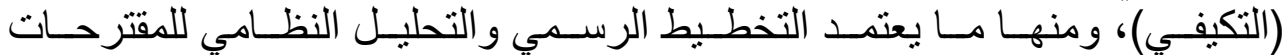

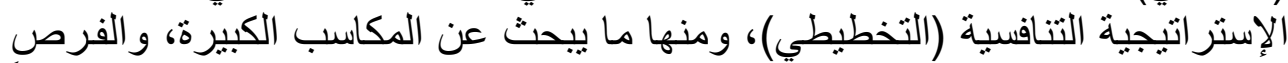

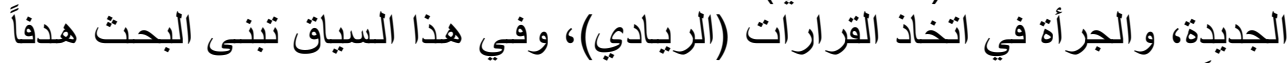

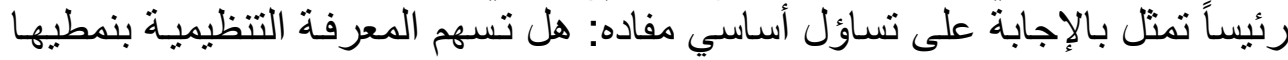

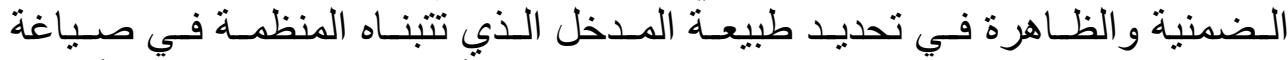

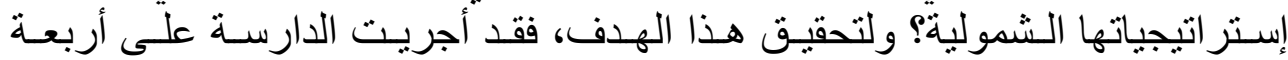

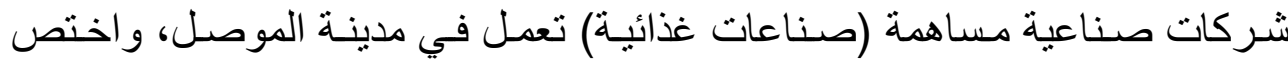
البحث بالإدارة العليا في هذه الثركات، وتم تقسيم البحث على المحاور الآتية:

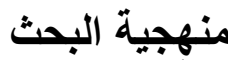 \\ أولاً - مشكلة البحث البحث}

تو اجه المنظمات المعاصرة تحديات كبيرة، تشكل تهديدات مستمرة لها، و هذا

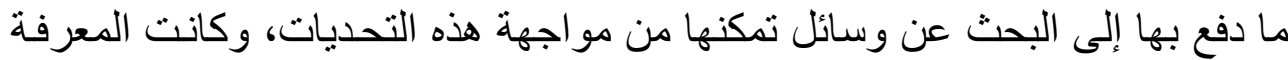

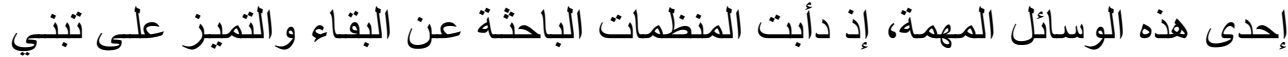

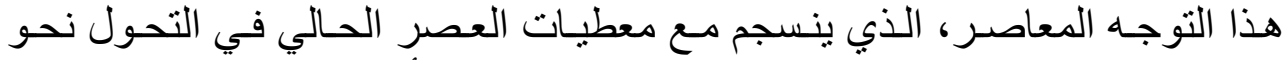

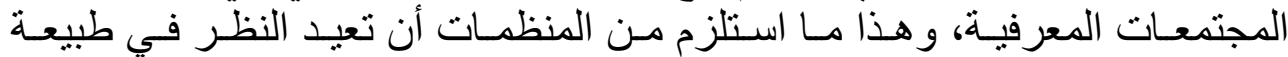

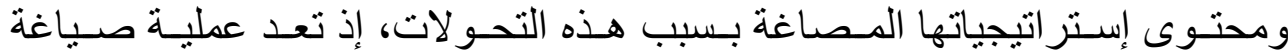

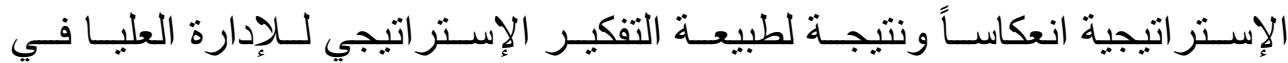

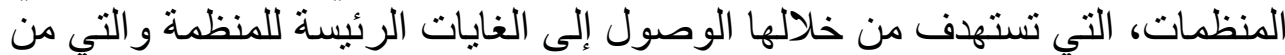

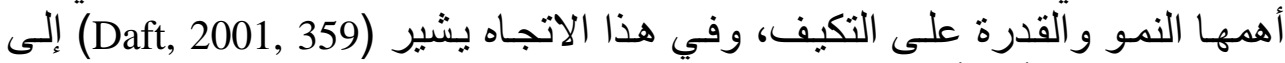

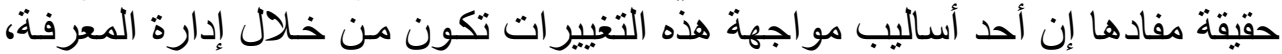

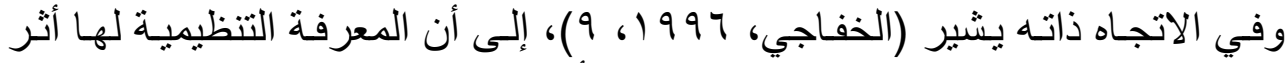

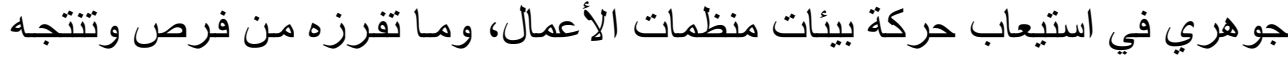

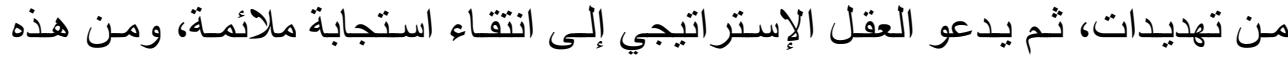
المنطلقات الفكرية تم تحديد مشكلة البحث من خلافل التساؤلات الآتية : 
ا. . هل ثتو افر المعرفة التنظيمية بنمطيها الظاهرة والضمنية في الثركات المبحوثة

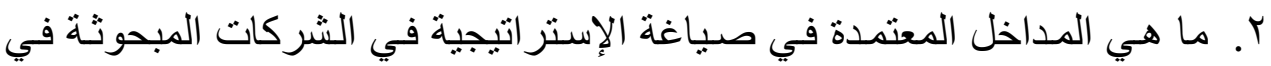

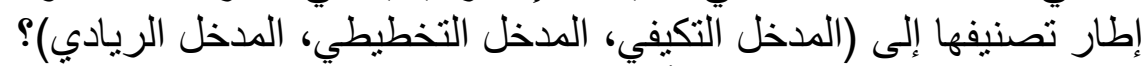

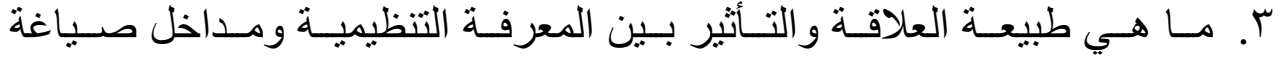
الإستر اتيجية هي مبن

\section{ثانياً. فرضيات البحث}

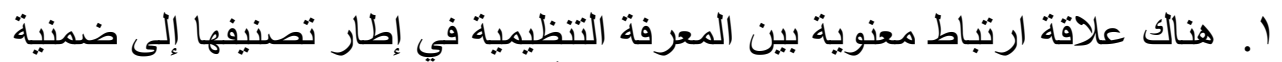
وظاهرة، ومداخل صياغة الإستر اتيجية وفقاً لتصنيفها إلى التكيفي والتهبية فيطيطي و الريادي. Y. تـؤثر المعرفـة التنظيميـة الـضمنية تـأثير اً معنويـاً فـي اختبـار مـدخل صـياغة الإستر اتيجية في الثركات المبرفة النموثة.

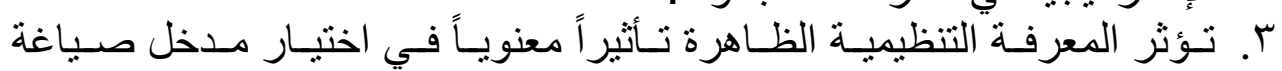
الإستر اتيجية في الثركات المبحوثة.

بأخذ البحث أهميتة الأكاديمية من تنأوله لموضوع يعد الأكثر رواجاً في إطسار ثالثاً. أهمية البحث

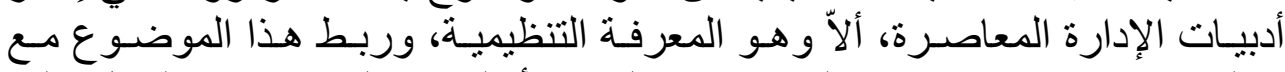

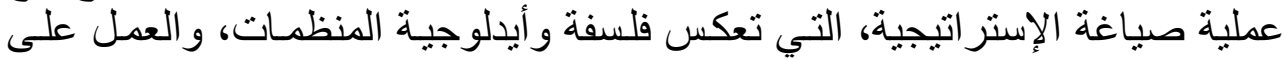

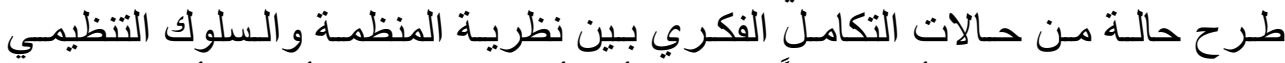

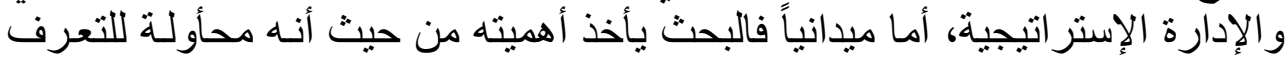

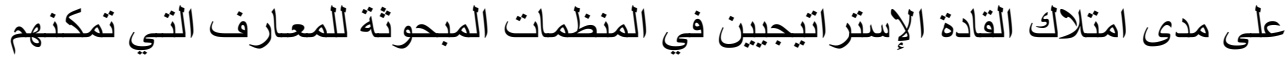

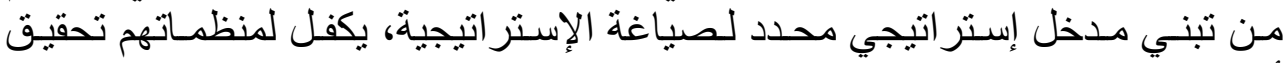
أهدافها الإستر اتيجية.

\section{رابعاً- أهداف البحث: يهدف البحث إلى تحقيق الآتي:}

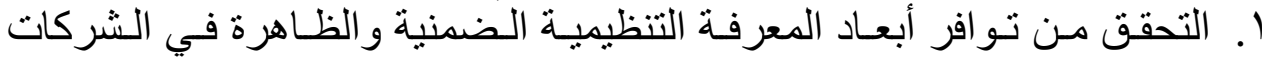

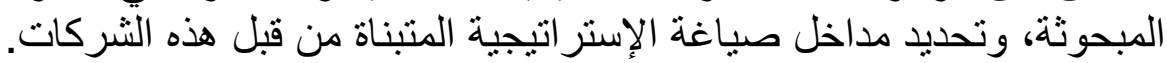
r r. تحديد طبيعة العلاقة بين المعرفة التنظيمية ومداخل صياغة الإستر اتيجية.

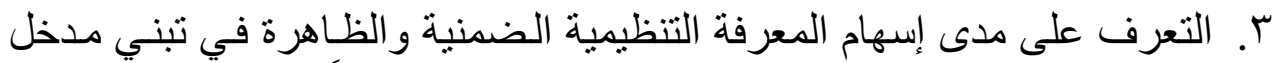

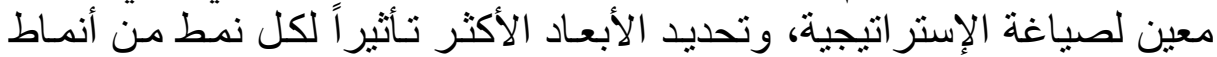
المعرفة في كل مدخل من هذه المداخل الإنل. خامساً. أدوات البحث في كل

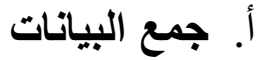

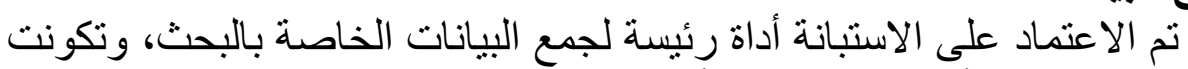

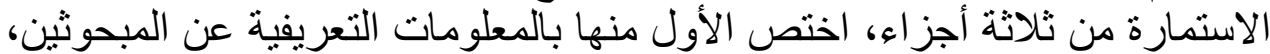




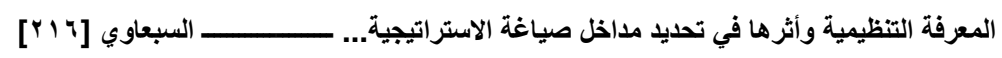

أما الجزء الثاني فاختص بقياس أنماط المعرفة التنظيمية الضمنية و الظاهرة، ولقد تم

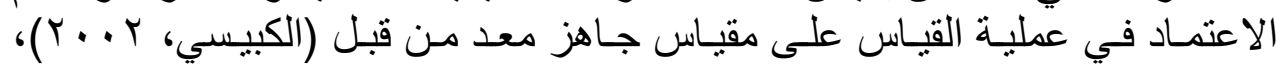

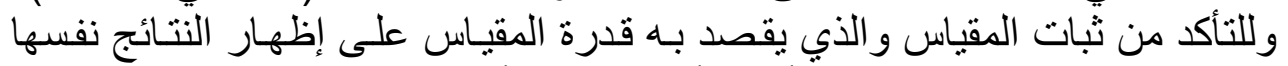

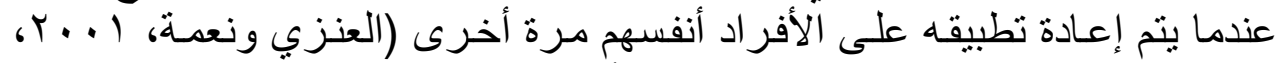

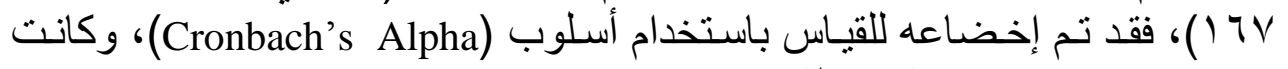

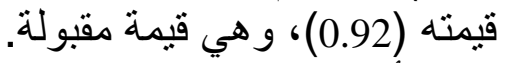

أما الجزء الثالث فقد اختص فئلة بمداخل صياغة إستر اتيجية المنظمة، وتم تصميم

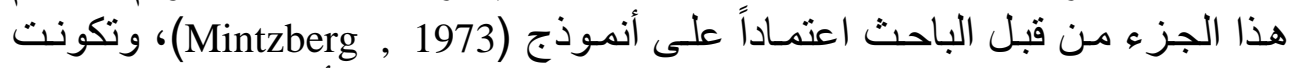

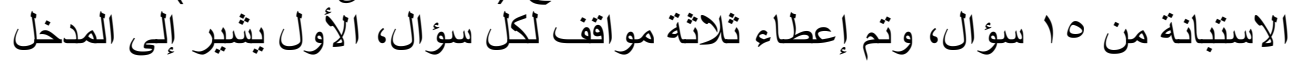

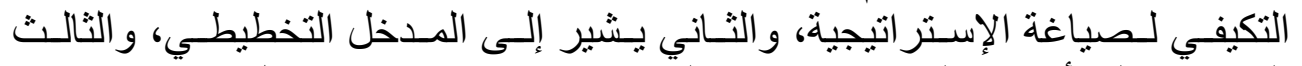

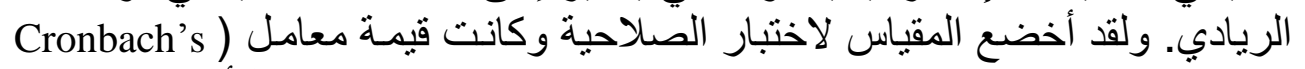

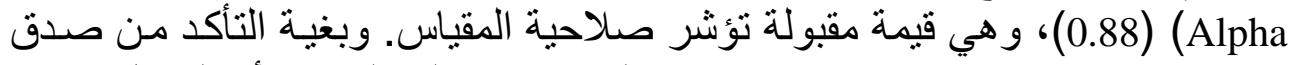

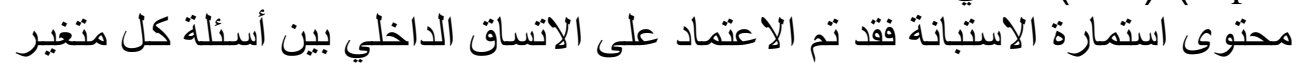

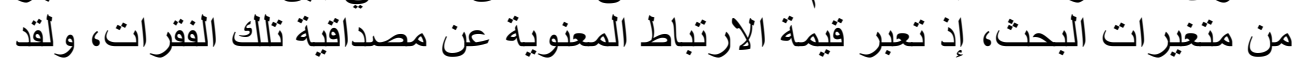

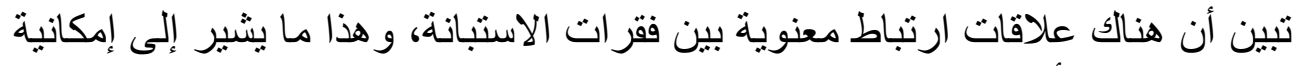
قياسها باعتماد أسئلة الاستبانة.

\section{ب. الأساليب الإحصائية}

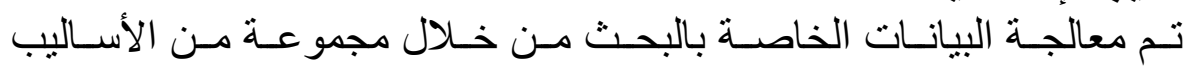

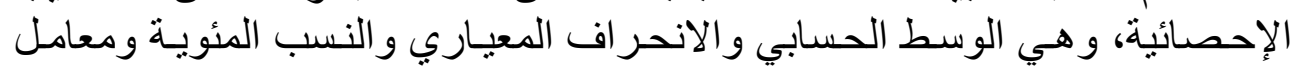

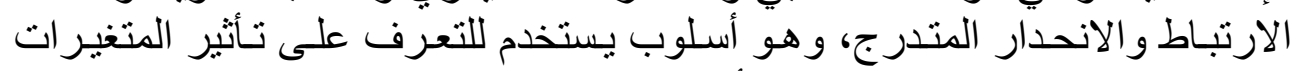

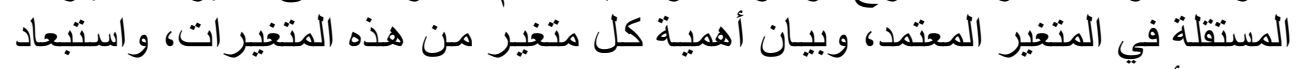

ذات التأثنر الضعيف فئفير الضعها.

\section{سادساً- عينة البحث}

تمثلت عينة البحث بأربعة شركات صناعية البه مساهمة (صناعات غذائيسة) في

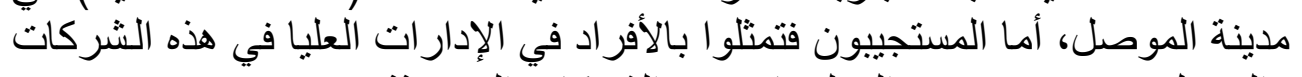
و الجدول ا يوضح بعض المعلومات عن الثركات المبحوثة. الإدئ.

\section{الجدول 1}

الثركات عينة البحث و وعدد الاستمارات المستلمة من كل شركة

\begin{tabular}{|c|c|c|c|c|}
\hline الملكية & العاملين & الاستمار عدات & التأسيسة & الشركة \\
\hline
\end{tabular}




\begin{tabular}{|c|c|c|c|c|c|}
\hline خاصنة & $* \varepsilon$. & $\wedge$ & 1974 & شركة الموصل للتعبئة و التغليف & 1 \\
\hline مختلطة & YII & IT & 1971 & والمعدنية للمنطقة الثمالية الغازية & r \\
\hline خاصنة & Ir. & 1. & 1919 & شركة نينوى للصناعات الغذائية & r \\
\hline \multirow[t]{2}{*}{ خاصة } & 11. & V & 1917 & شركة الحدباء لمنتجات الالبان & $\varepsilon$ \\
\hline & & TV & & المجموع & \\
\hline
\end{tabular}

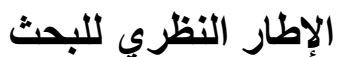

\section{أولاًا- المعرفة التنظيمية/المفهوم والتصانيف}

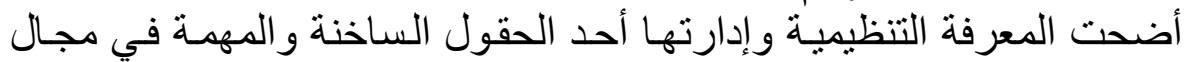

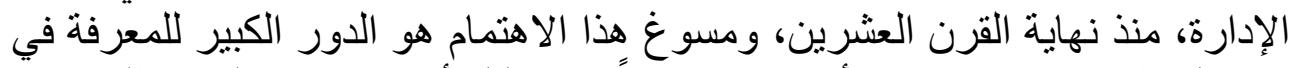

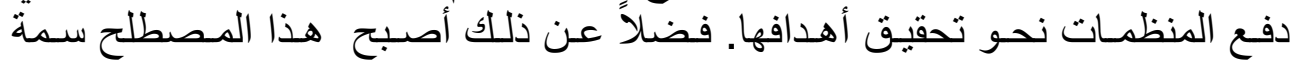

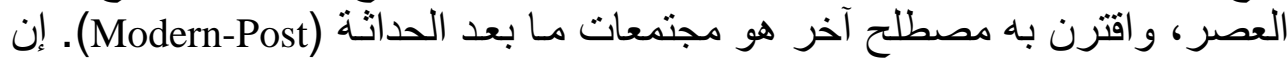

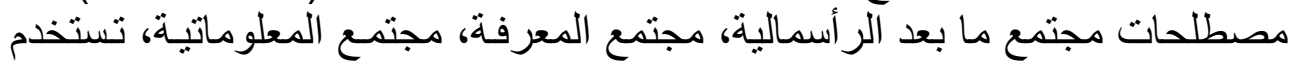

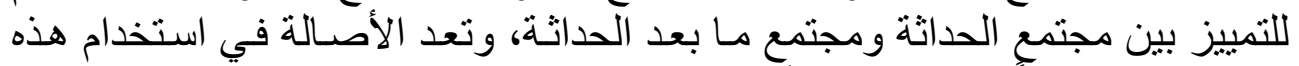

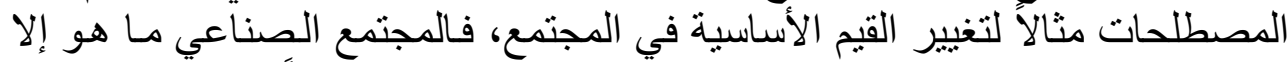

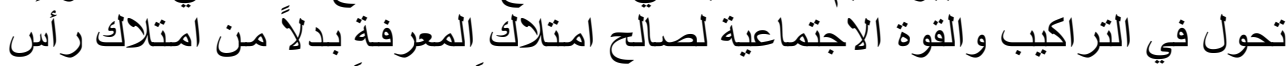

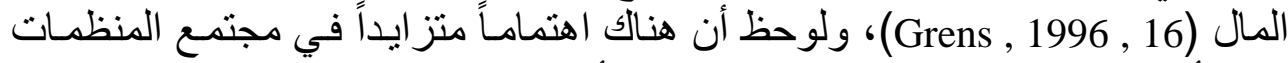

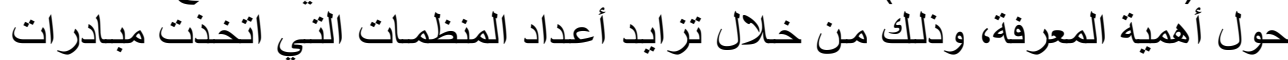

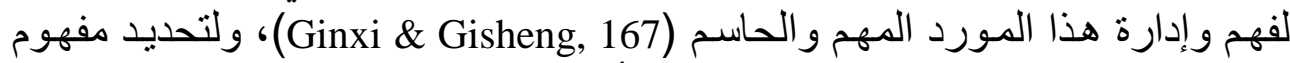
المعرفة التنظيمية كان هناك الكثير من المحأو لات لوضع تعريف محدد وو اضح لهذا لهونا

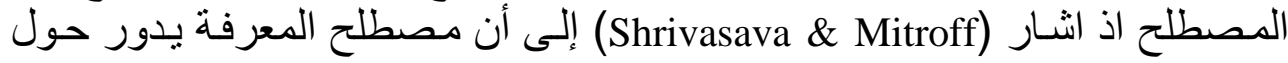

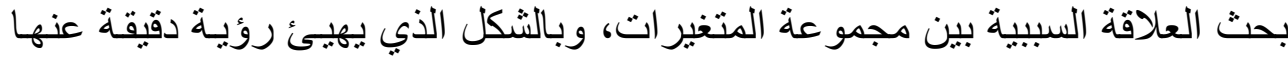

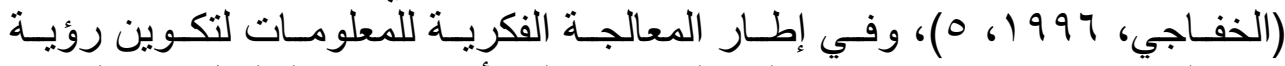

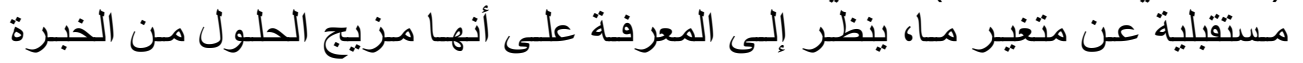

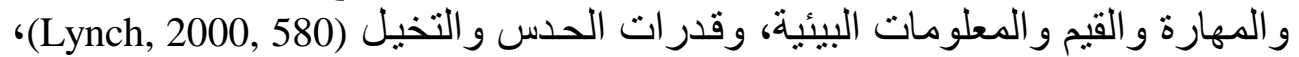

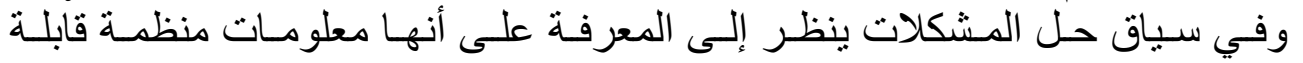

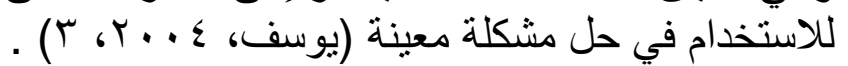

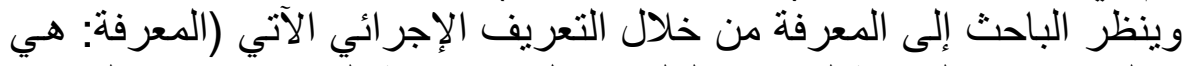

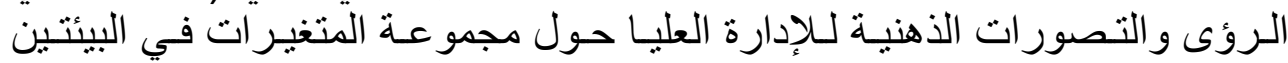

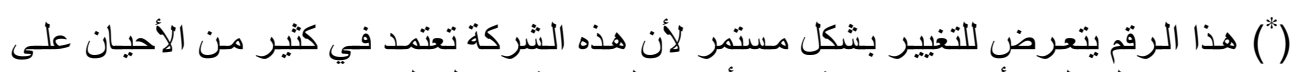

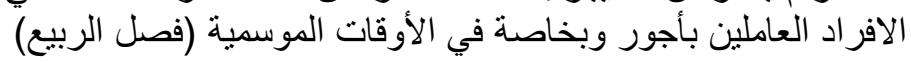




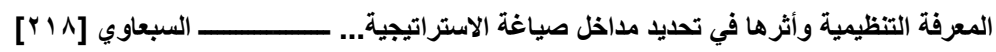

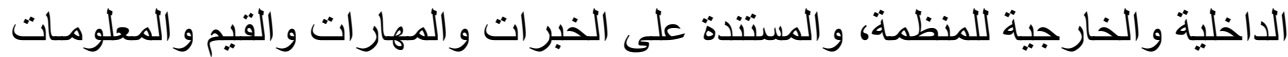

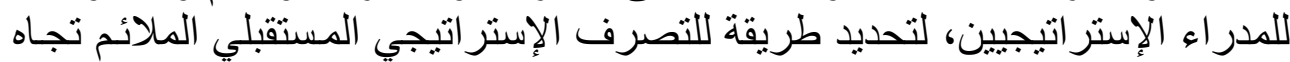

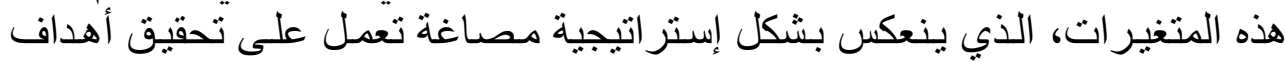
المنظمة و غذاياتها).

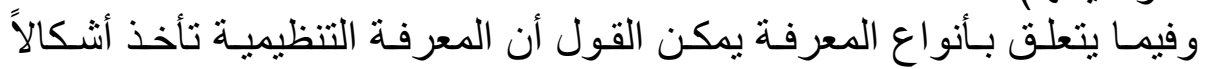

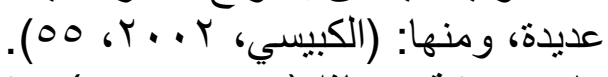

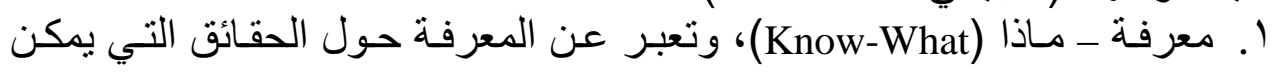
ترميز ها.

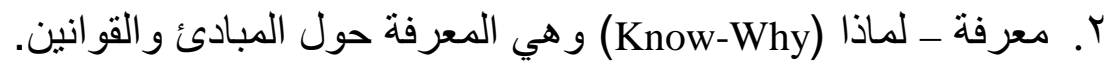

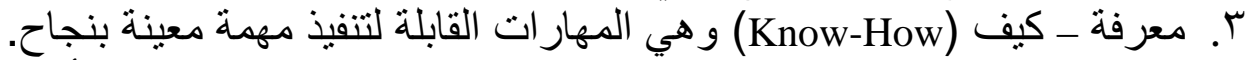

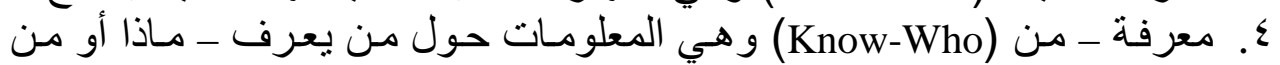
يعرف كيفية أداء ماذا. وفي سياق الربط بين المعرفة والإستر اتيجية طرح (Zack, 1999) تصنيفه في إطار ما يعرف بخريطة المعرفة (Knowledge Map)، إذ إن تقيبم الموقف (إنف المعرفي

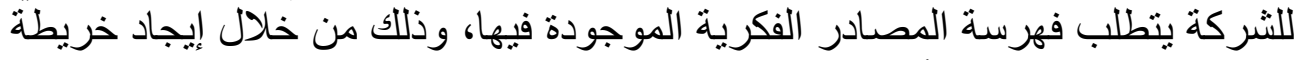

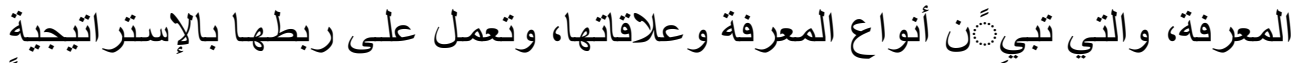

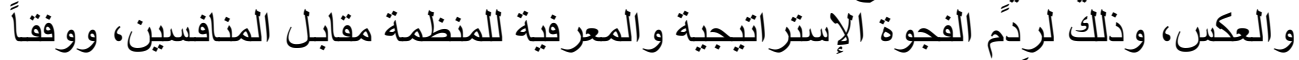

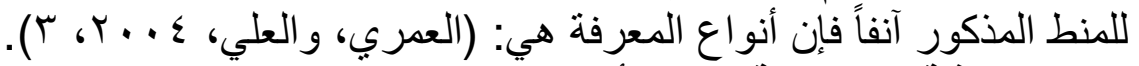

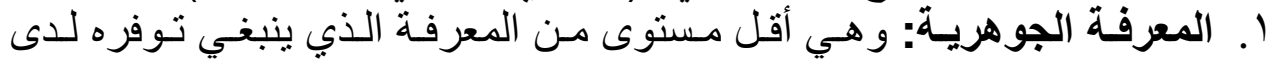
المنظمة لمو اجهة المنافسين.

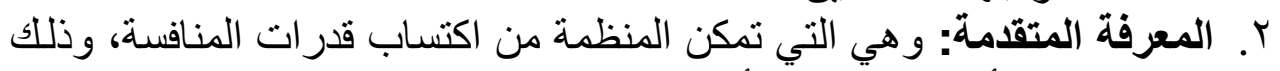

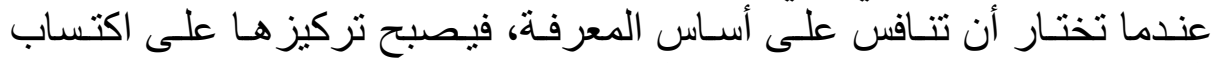

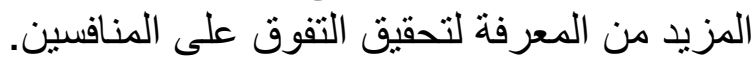

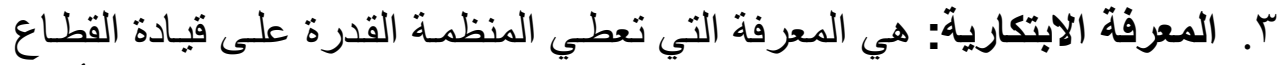

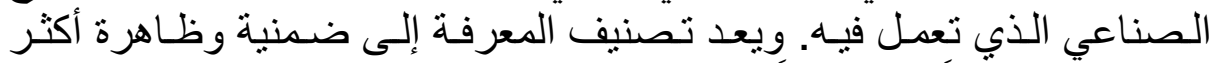

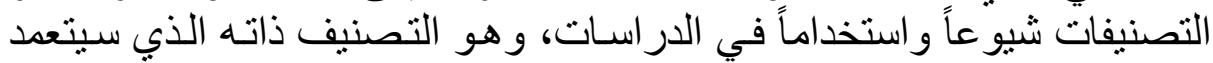
في البحث الحالي.

\section{ا ـ المعرفة الضمنية}

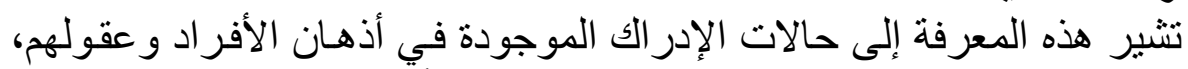

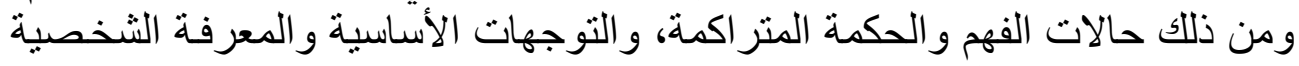

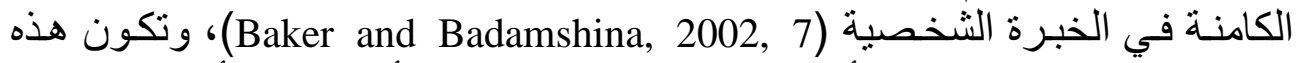

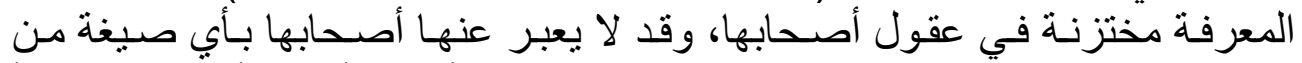

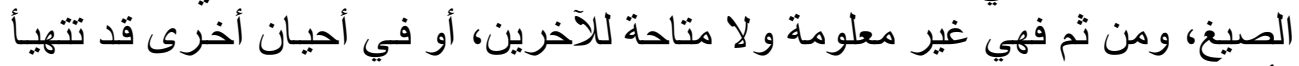

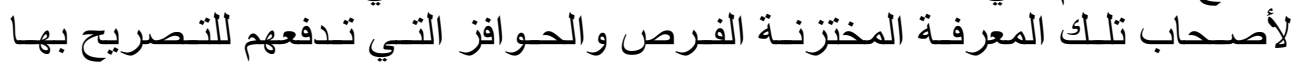




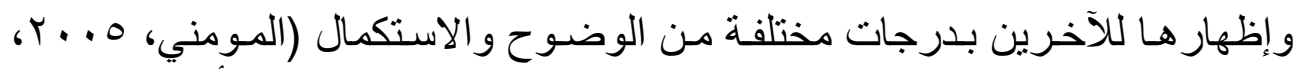

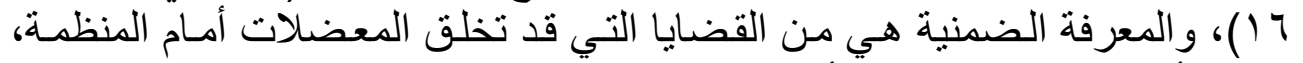
وذللك لأنها قد تكون خاطئة، و أنه من الصعب تنغ تغيير ها، وهي غير مرئية ومن ثم فمن

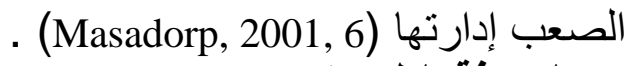

r ب. المعرفة الظاهرة

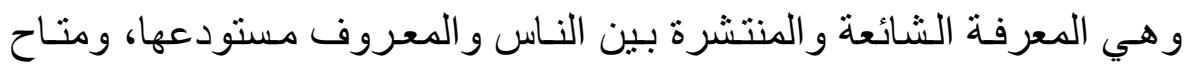

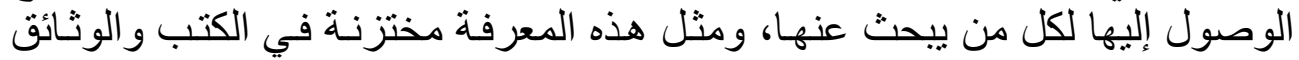

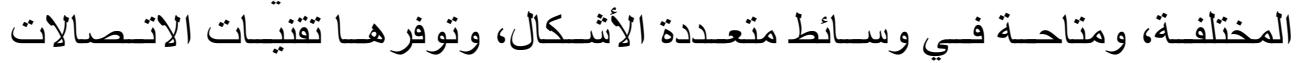

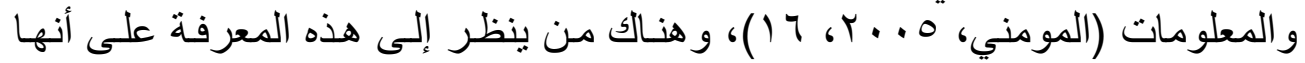

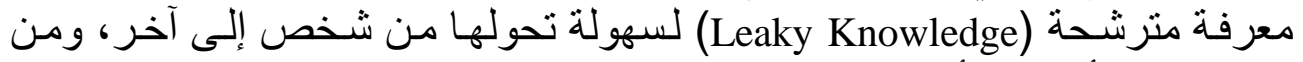

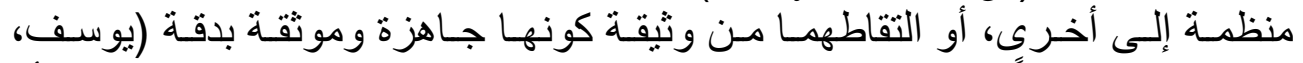

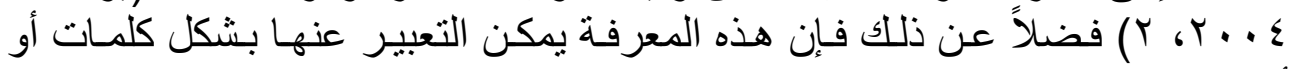

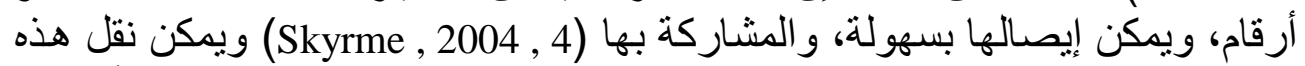

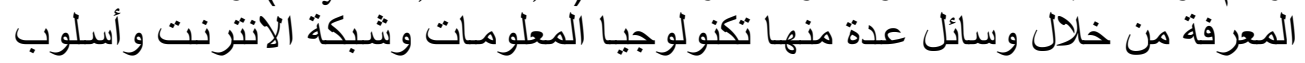

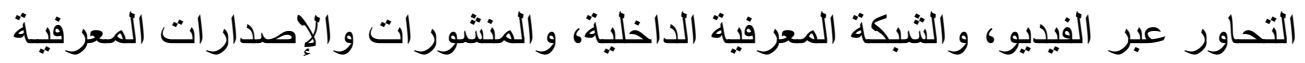

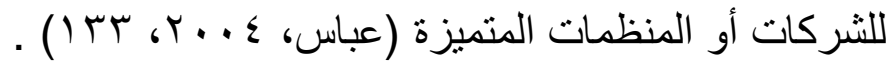

ثانياً. صياغة الإستراتيجية: المفهوم والمداخل

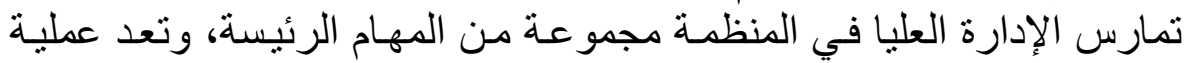

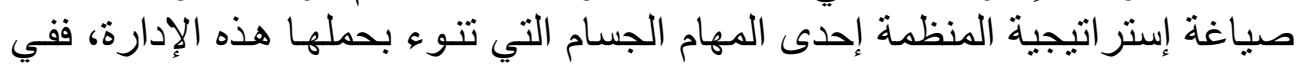

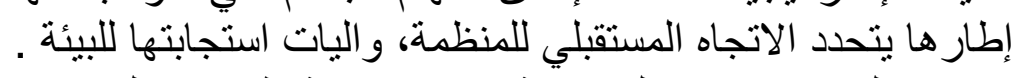

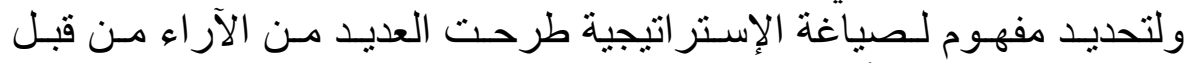

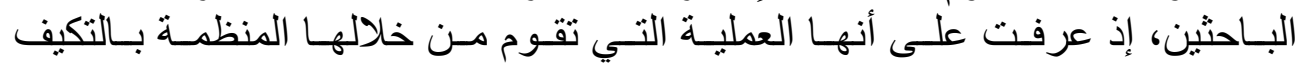

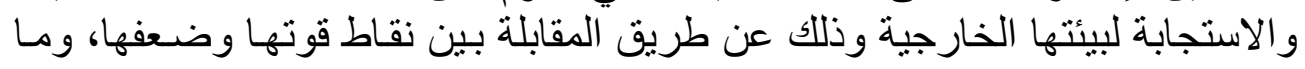

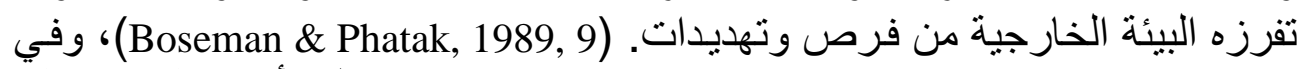

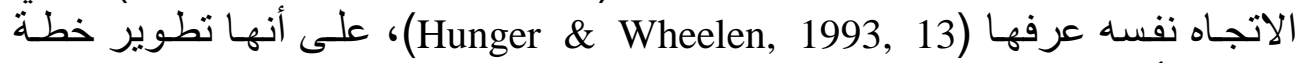

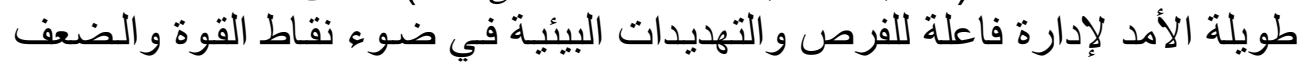
المنظمية.

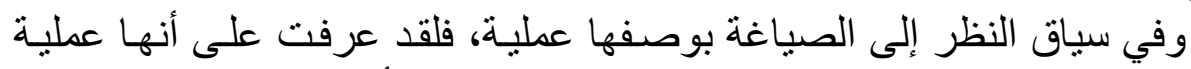

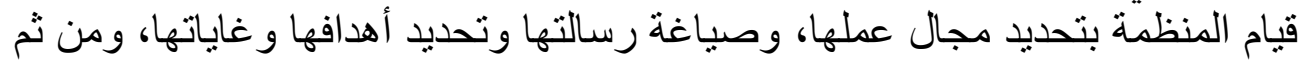

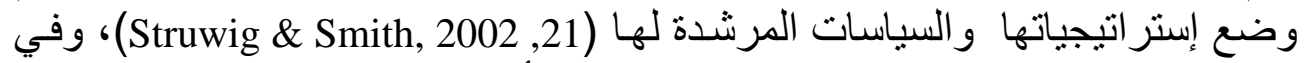

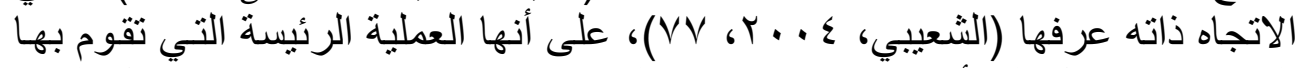

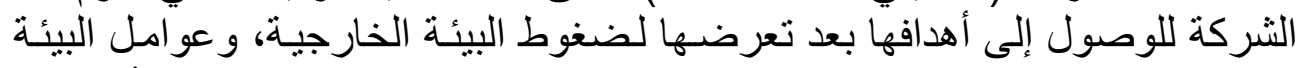

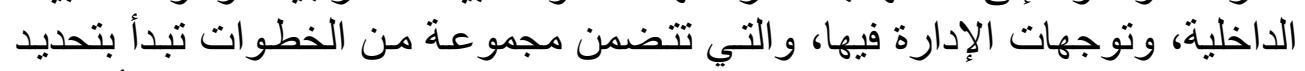

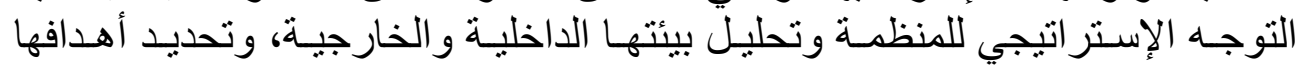

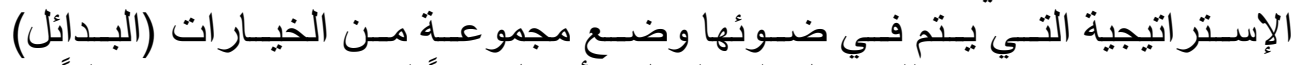
الإستر اتيجية، ثم تقييمها للوصول إلى البية البديل الأفضل وفقاً لمعايير تم تحديدها سلفاً. 


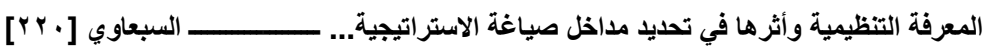

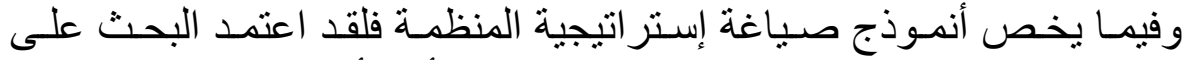

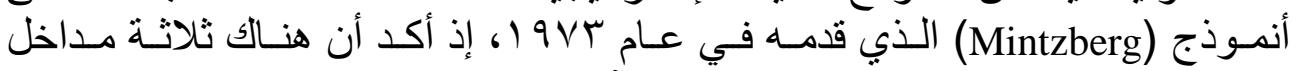

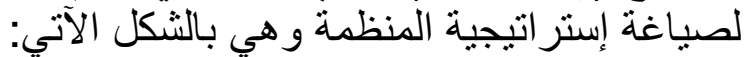

the entrepreneurial Approach المدخل الريادي:

يعتمد هذا المدخل في صياغة الإستر اتيجية على رؤيسة وبصيرة التوجه لدى الدى

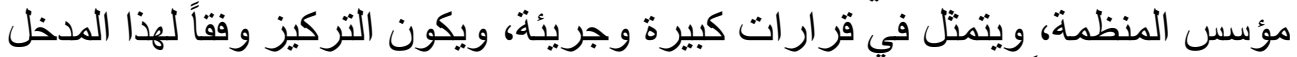

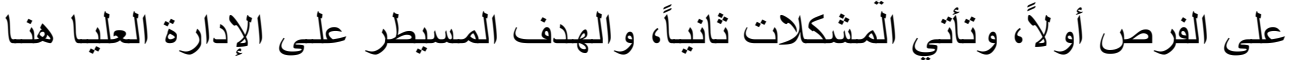

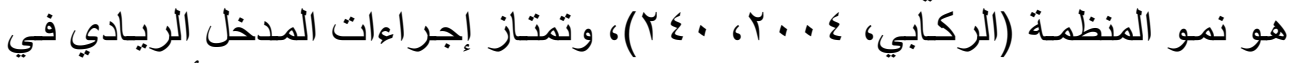

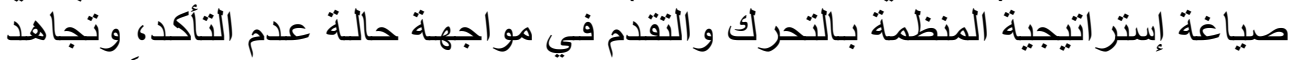

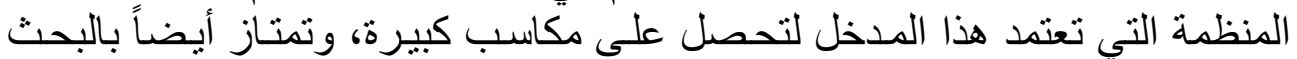

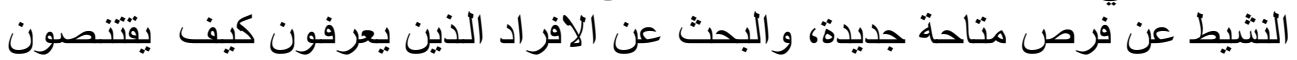

الفرص (Quinn, et. al., 1988, 83).

The Adaptive Approach المدخل التكيفي (8)

إن المنظمات التي تعتمد هذا المدخل في الصياغة تمتاز بأنها تحكمها مجمو عة التها

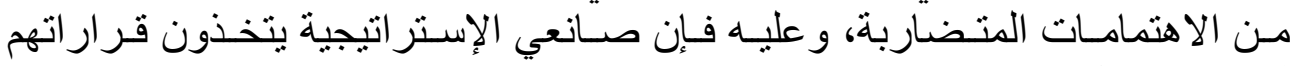

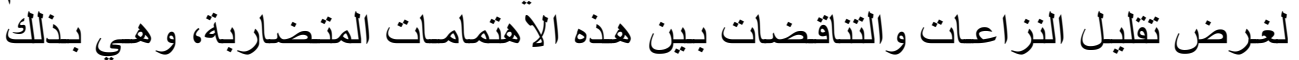

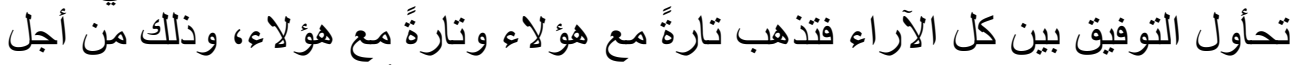

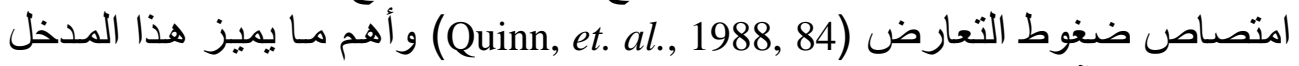
الخصائص الآتية (برق، ا. تالتسم الاهداف المحددة من قبل المنظمة هونة بعدم الوضوح، و وإنما تكون انعكاسـاً لقوة

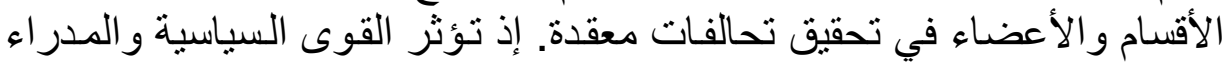
و المالكون و النقابات كُل حسب حجم قو تهاء في في عملية صياغة الإستر اتيجية.

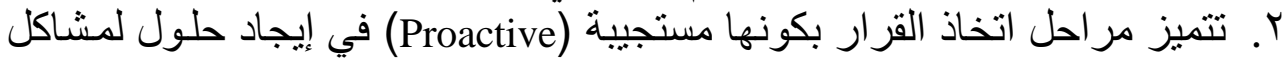

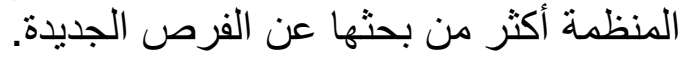

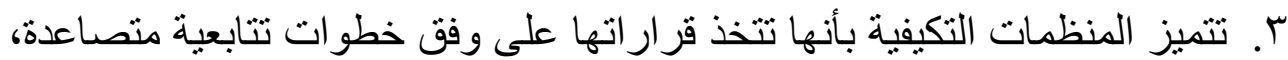

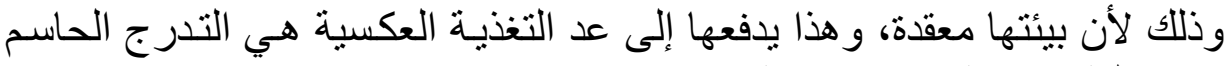
في عملية صياغة الإستر اتيجية.

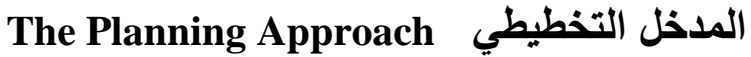

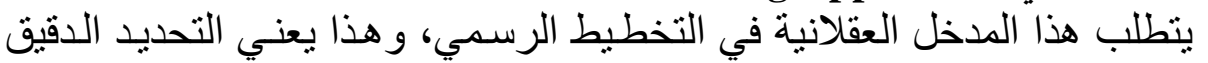

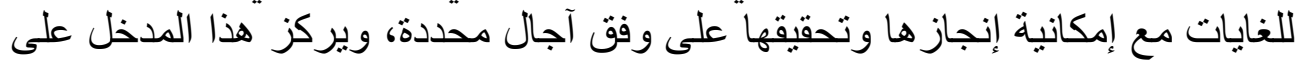

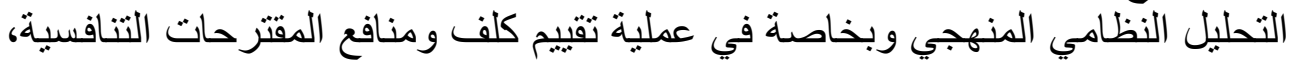

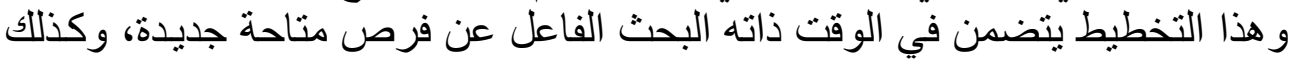

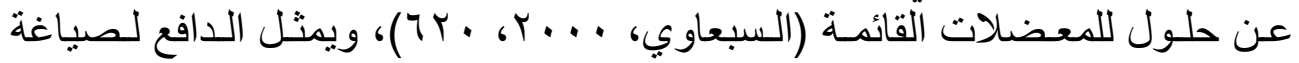
الإستر اتيجية ضمن هذا المدخل كلا من رد الفعل (Reactive) نحو المتغيرات التهن البيئيـة

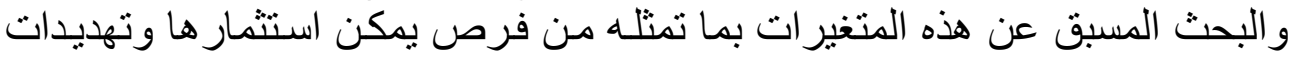

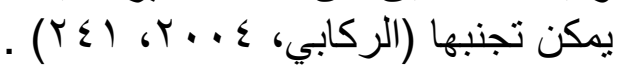




\section{الإطار الميداني للبحث

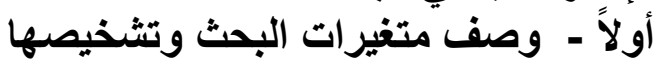

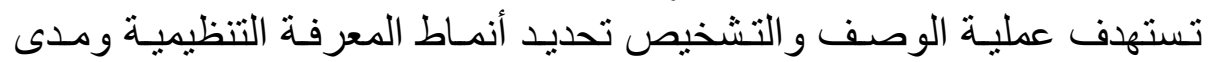

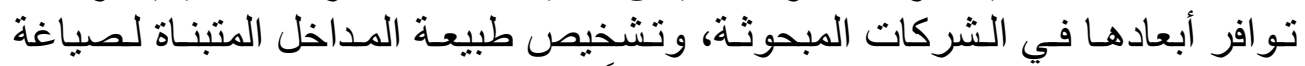

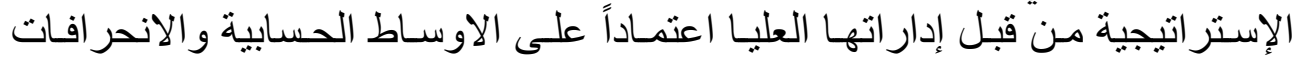

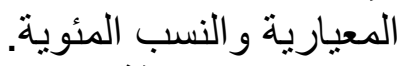

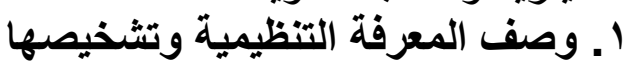

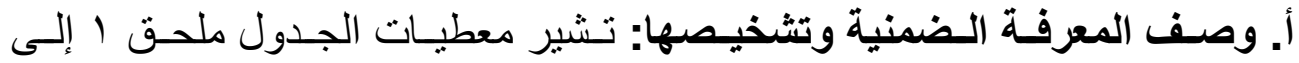

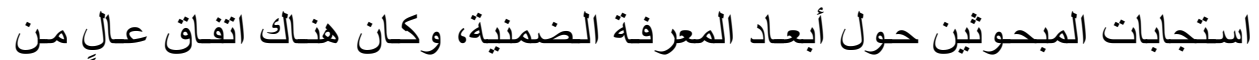

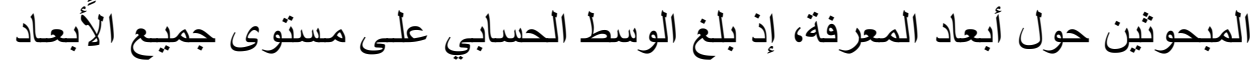

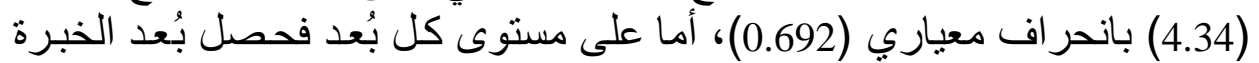

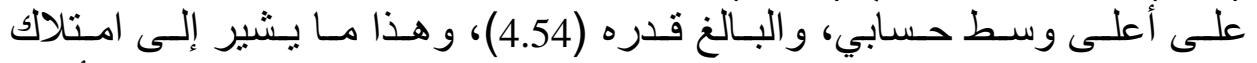

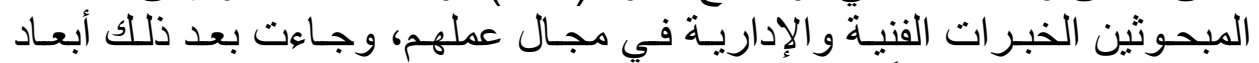

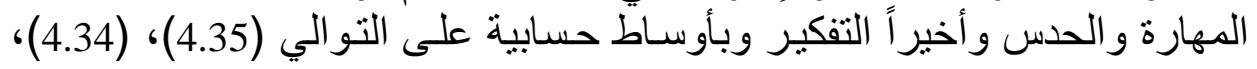
(4.12) وبانحر افات معيارية (0.698) و الفير الفير (0.855) و (0.691).

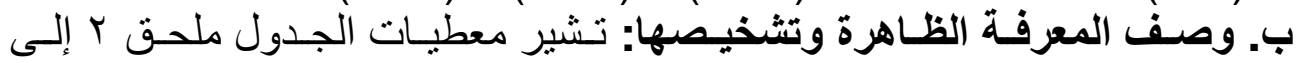

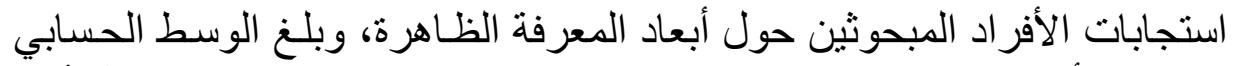

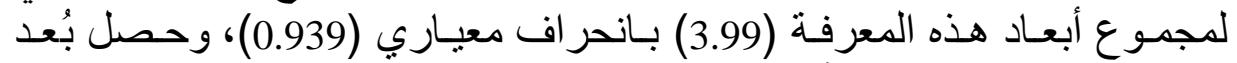

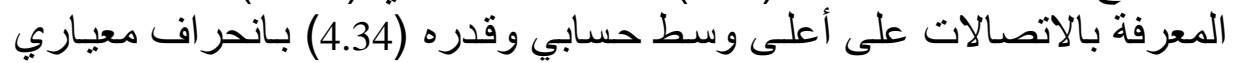

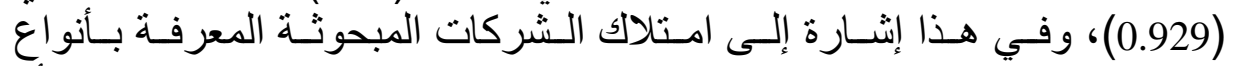

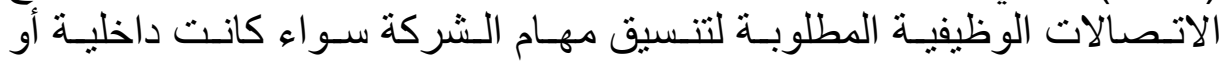

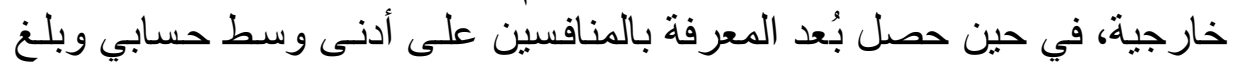

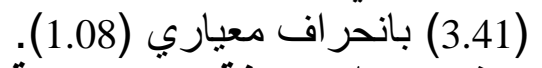
r . وصف مداخل صياغة الإستر اتيجية

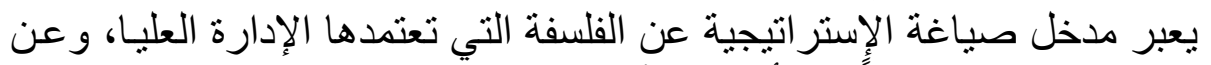

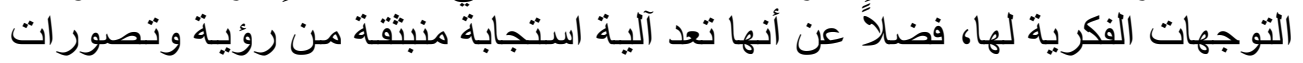

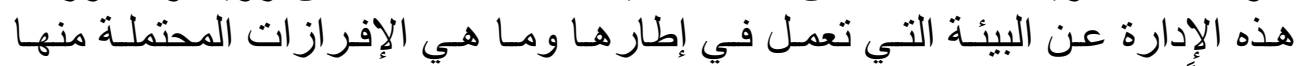

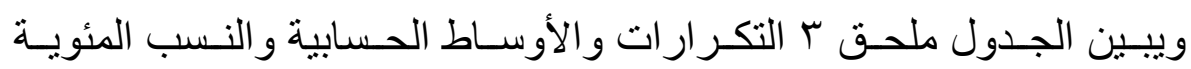
مستقبِلاً.

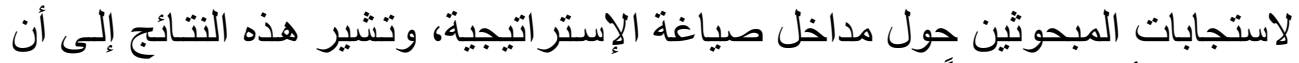

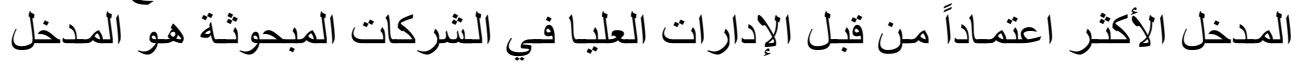

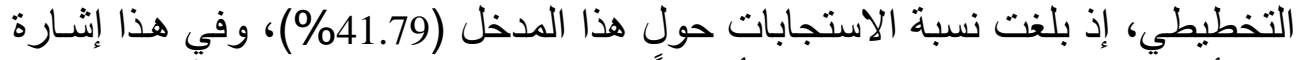

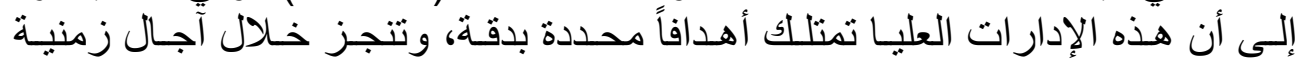

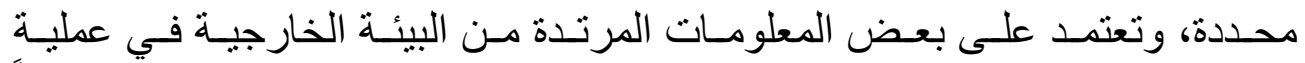

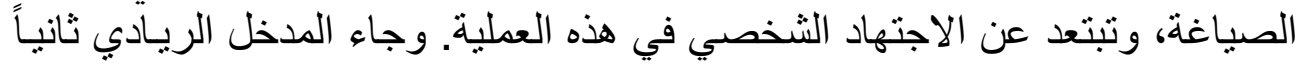

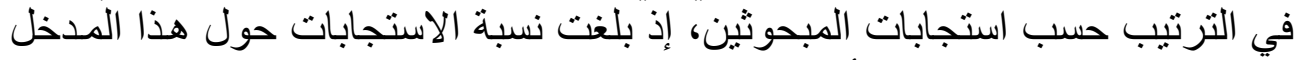

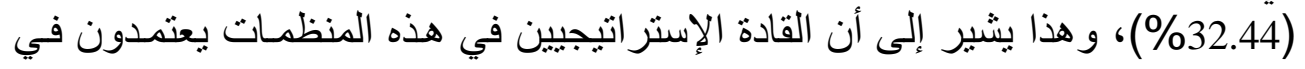




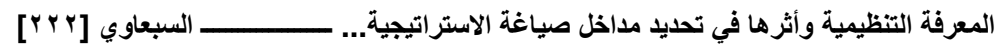

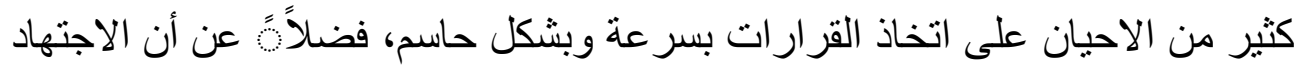

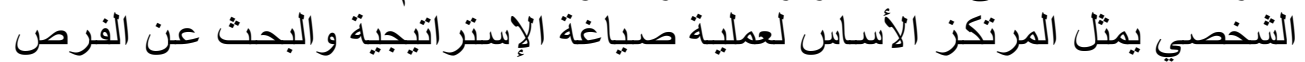

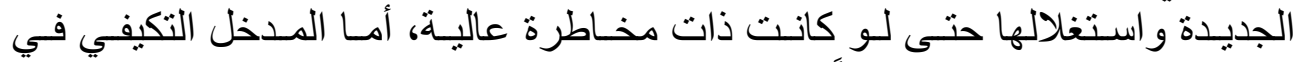

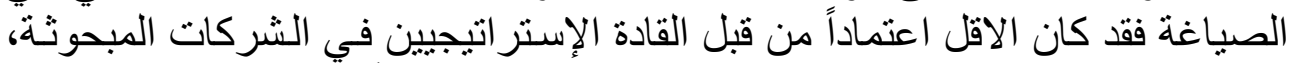

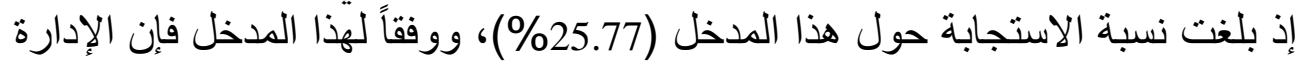

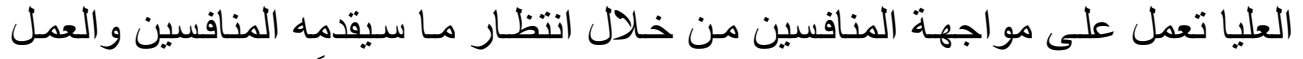

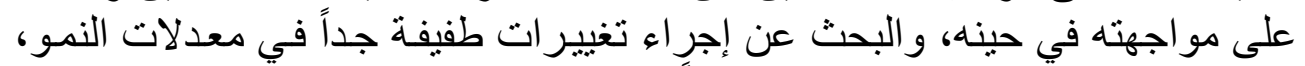

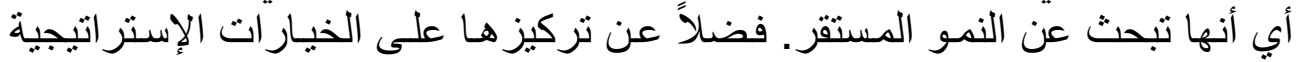

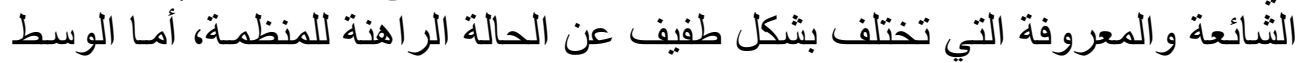

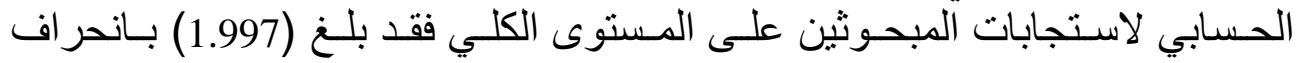
معياري (0.677).

\section{ثانياً- اختبار فرضيات البحث}

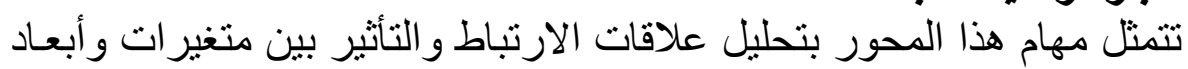

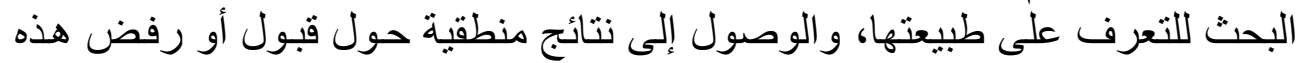

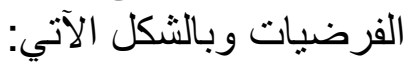

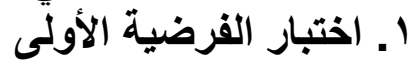

نصت هذه الفرضية على الألى وجود علاقة معنوية بين المعرفة التنظيمية في إطـار

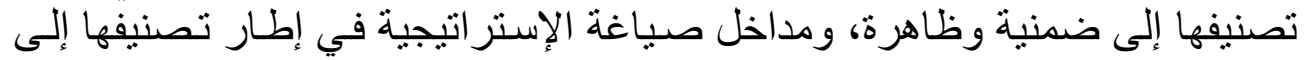

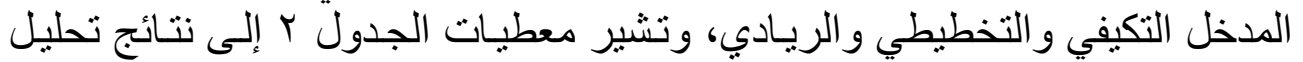

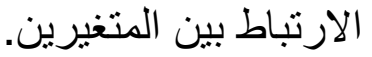

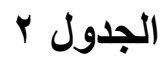

علاقات الارتباط بين المعرفة الضمنية ومداخل صياغة الإستراتيجية

\begin{tabular}{|c|c|c|c|c|c|}
\hline المؤشر الكلي & التفكير & المهارة & الخبرة & الحسس & مدخل الصياغة المعرفة الضمنية \\
\hline $0.647 * *$ & $0.824 * *$ & $0.643^{* *}$ & $0.501 * *$ & $0.532 * *$ & التكيفي \\
\hline $0.388^{*}$ & $0.344 *$ & 0.155 & $0.544^{* * *}$ & $0.449^{* *}$ & التخطيطي \\
\hline $0.909 * *$ & $0.846^{* *}$ & $0.865^{* *}$ & $0.927 * *$ & $0.886^{* *}$ & الريادي \\
\hline
\end{tabular}

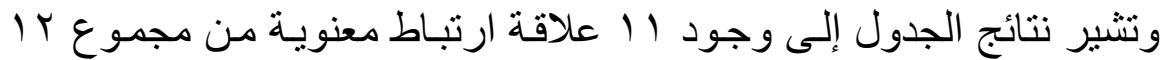

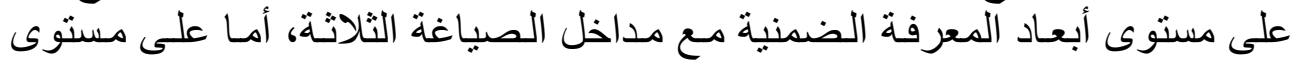

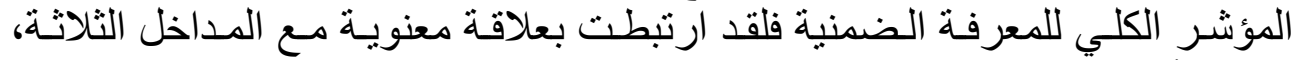

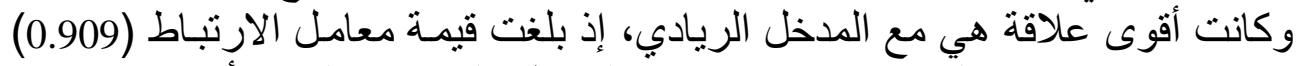

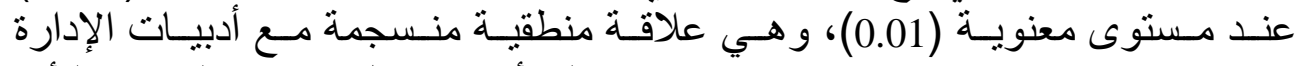

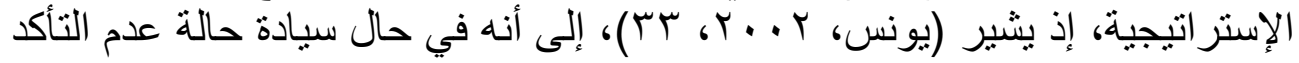




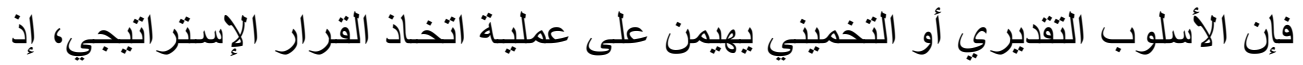

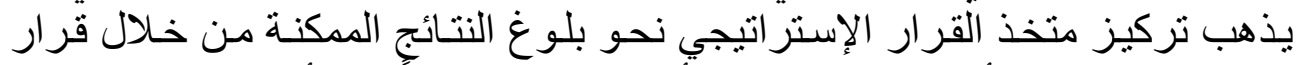

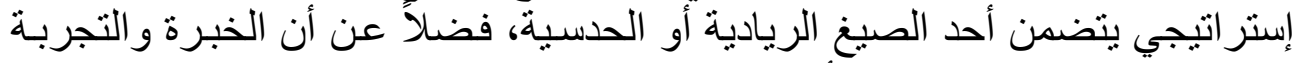
الناجمة عن مسيرة طويلة تعد أداة في رفئ التهد التفسير الذاتي للمستقبل. و ارتبطت المعرفة الضمنية بعلاقة مع المدخل التكيفي أقل قوة مـن سن سـابقاتها،

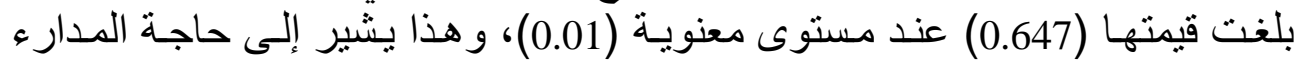

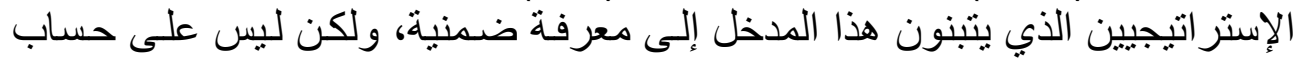

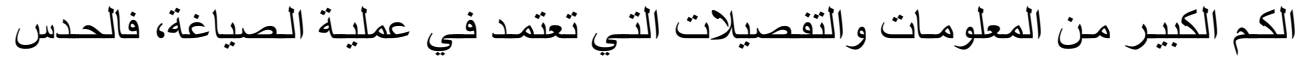

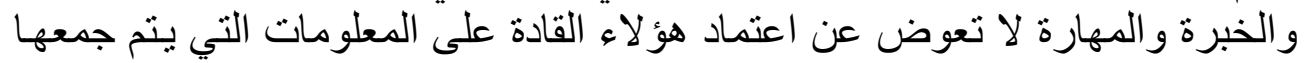

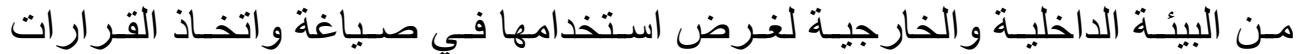

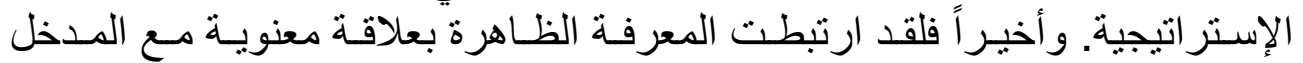

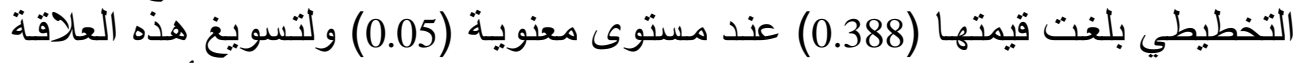

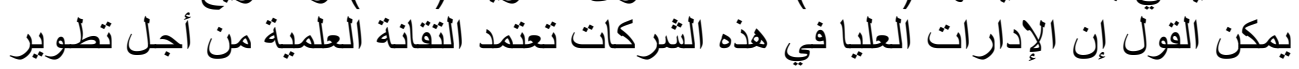

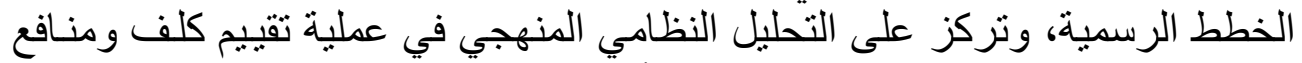

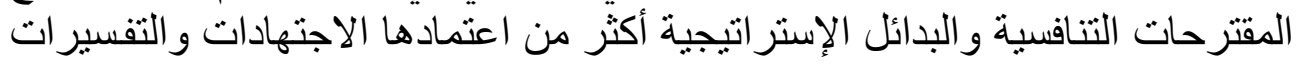

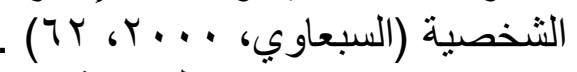

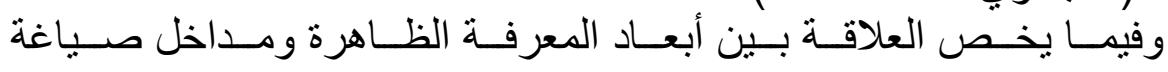

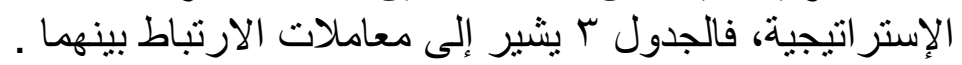




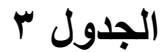

علاقات الارتباط بين المعرفة الظاهرة ومداخل صياغة الإستراتيجية

\begin{tabular}{|c|c|c|c|c|c|c|c|}
\hline الكلئش & المنافربين & الموردين & التقنية & الاتصالات & الزيون & المعوقة & مدخل الصياعة فلمة الظاهرة \\
\hline $0.683^{* *}$ & $0.832 * *$ & $0.601^{* *}$ & $0.746^{* *}$ & 0.423 ** & $0.684^{* *}$ & $0.633^{* *}$ & تكيفي \\
\hline $0.352 *$ & 0.157 & $0.326^{*}$ & 0.313 & $0.572 * *$ & $0.327^{* * *}$ & $0.404 *$ & تخطيطي \\
\hline $0.913^{\star \star}$ & $0.855^{* *}$ & $0.913^{* *}$ & $0.882 * *$ & $0.888^{* *}$ & $0.809^{* *}$ & $0.913^{* *}$ & ريادي \\
\hline
\end{tabular}

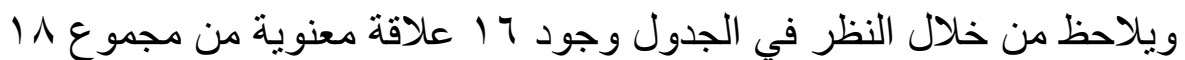

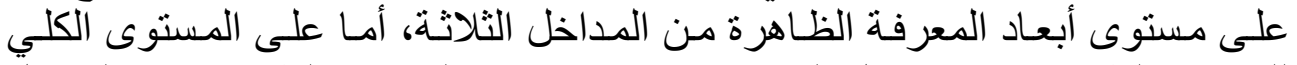

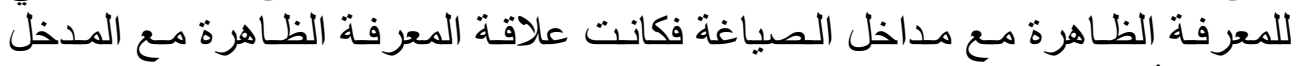

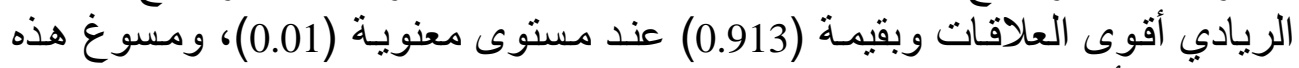

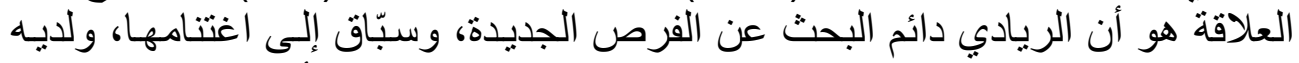

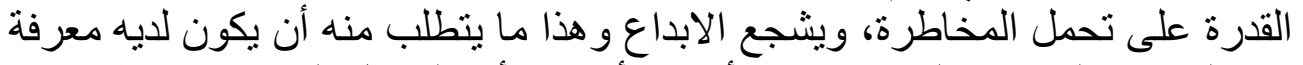

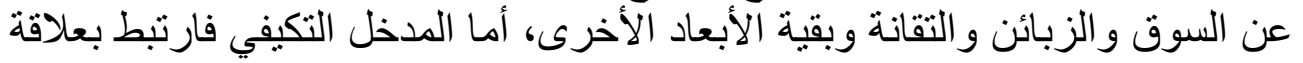

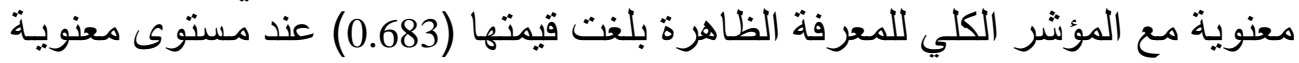

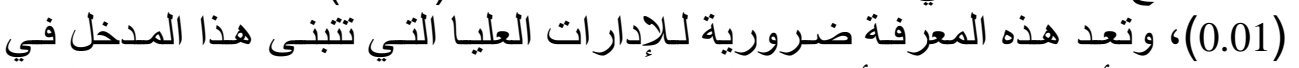

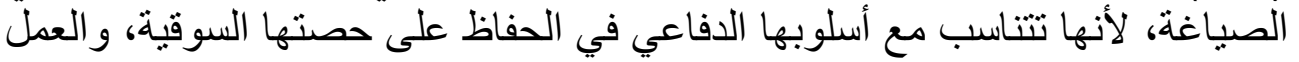

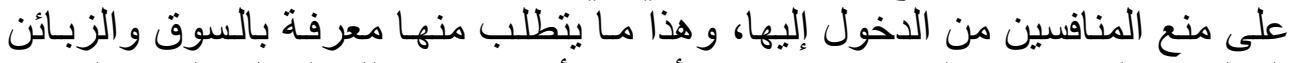

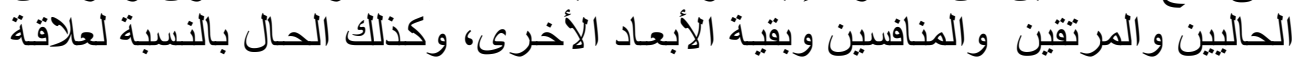

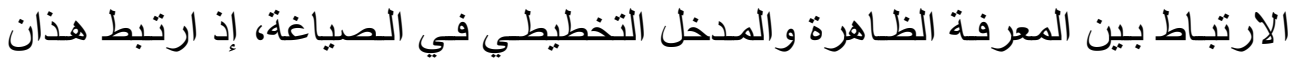

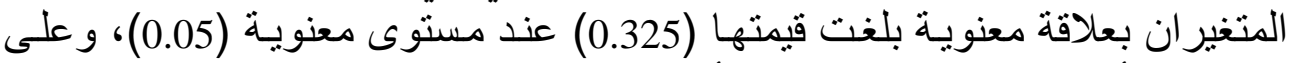

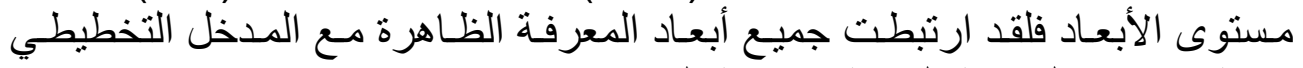

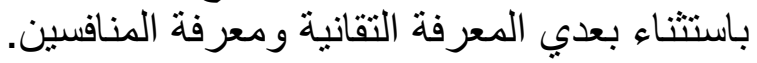
وفي ضِو ما ورد من نتائج فإن البحث يقبل بالفرضية الأولى.

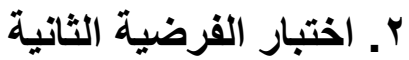

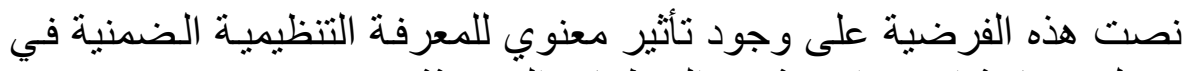

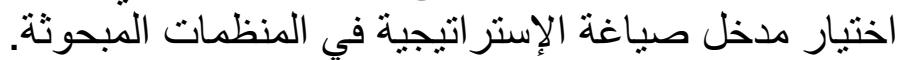

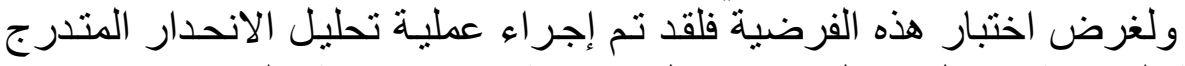

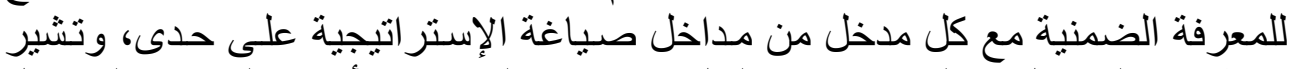

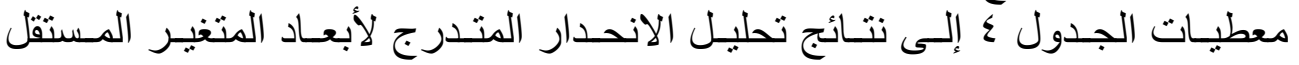
(المعرفة الضمنية) في المتغير المعتمد (المدخل التكيفي). 


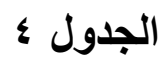

نتائج تحليل الانحار المتلدرج لتأثير المعرفة الضمنية في المدخل التكيفي

\begin{tabular}{|c|c|c|c|c|}
\hline d.f & F F المحسوبة F & $\mathbf{R}^{2}$ & B & المعرفة الضمنية مؤشرات التحليل \\
\hline$(1,35)$ & 214.10 & 0.859 & 0.927 & الخبرة \\
\hline$(2,34)$ & 121.66 & 0.877 & $0.241,0.726$ & الخبرة + التفكير \\
\hline
\end{tabular}

$\mathrm{N}=37$

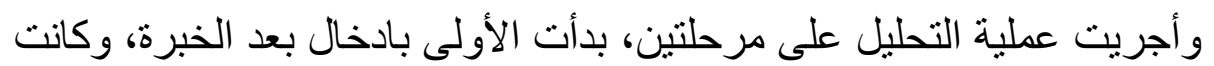

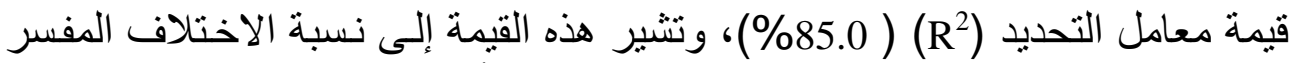

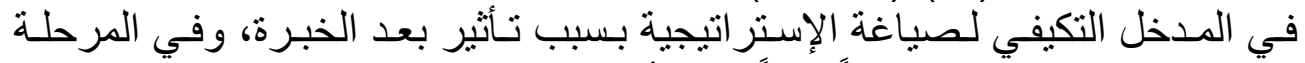

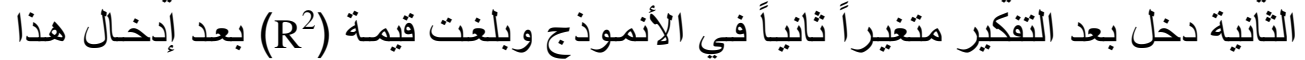

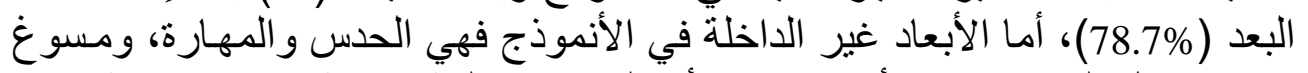

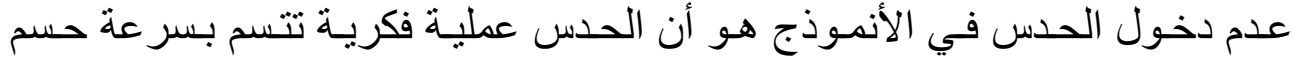

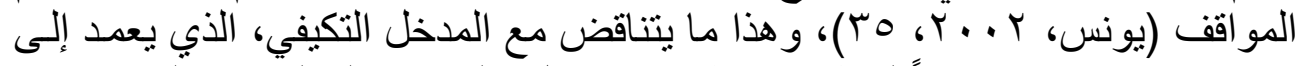

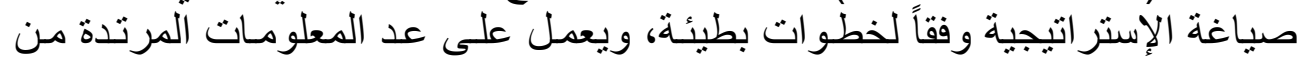

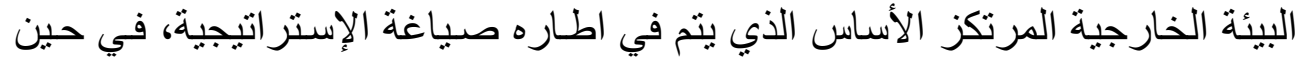

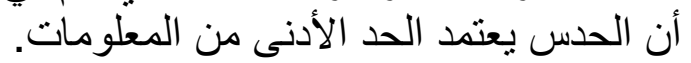

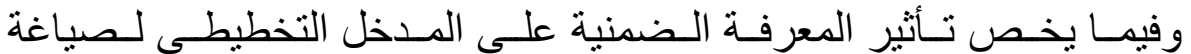

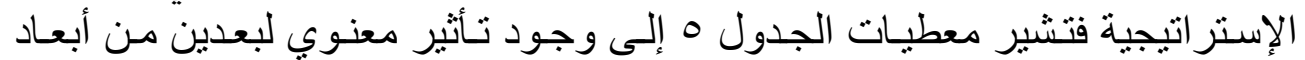
المعرفة الضمنية في هذا المدخل.

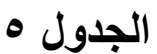

نتائج تحليل الانحدار المتدرج لتأثير المعرفة الضمنية في المدخل التخطيطي

\begin{tabular}{|c|c|c|c|c|}
\hline d.f & F المحسوبة & $\mathbf{R}^{2}$ & B & المع فة الضمنـة مؤشرات التحليل \\
\hline$(1,35)$ & 14.69 & 0.296 & 0.544 & الخبرة \\
\hline$(2,34)$ & 23.79 & $0.966,1.34$ & 0.583 & الخبرة + التفكير \\
\hline
\end{tabular}

$\mathrm{N}=37$

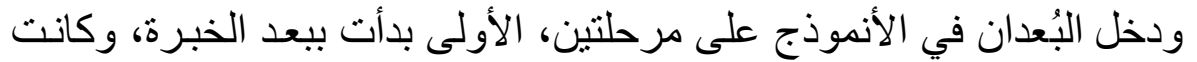

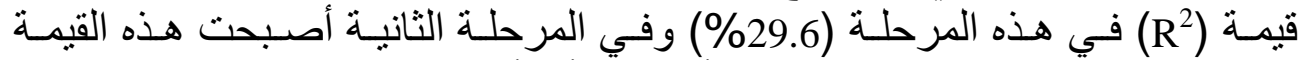

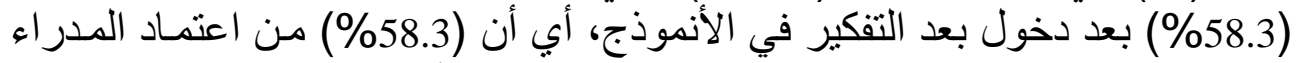

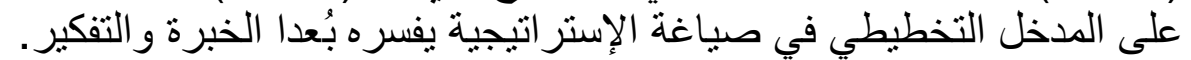

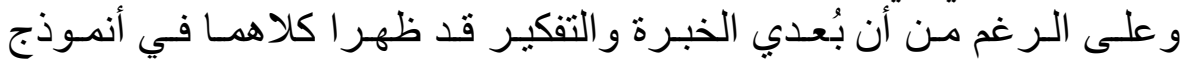

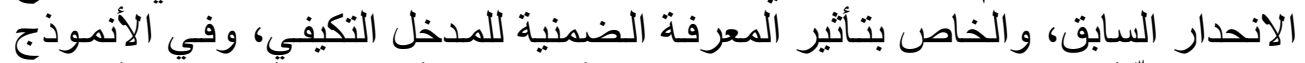
الحالي، إلاً أن قدرة المتغيرين التفسيرية كانت أكبر في الأنموذج الأول من الأنموذج الأنهوذج 


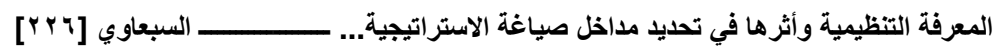

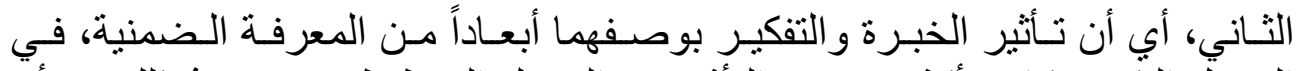

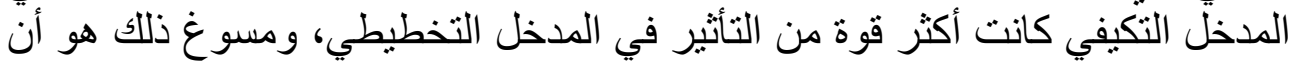

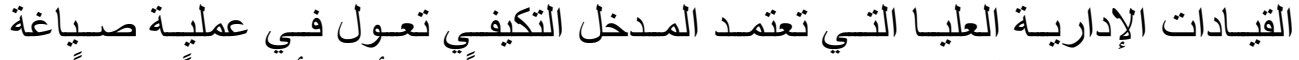

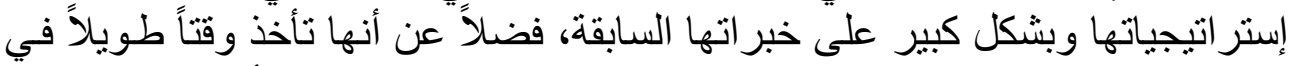

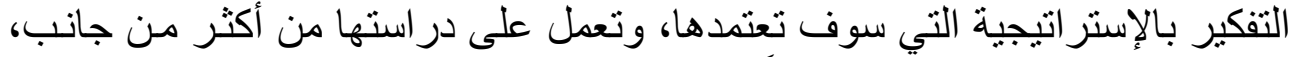

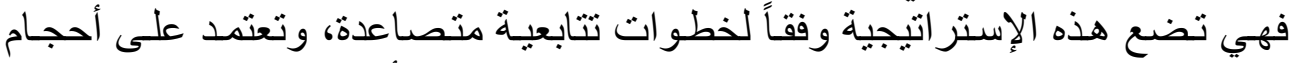

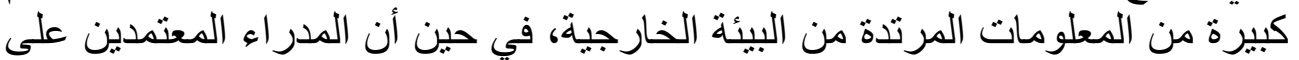

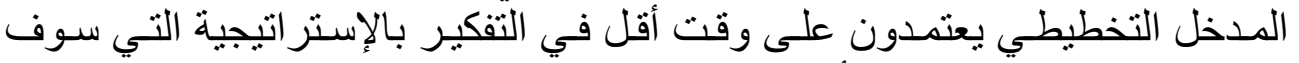

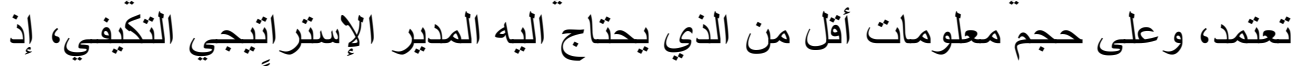

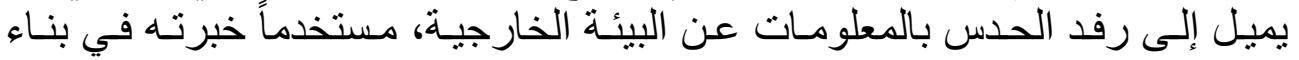

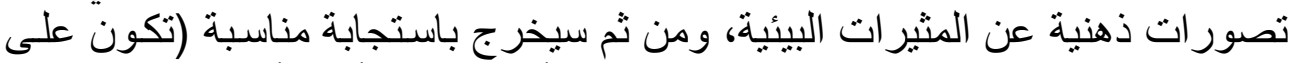

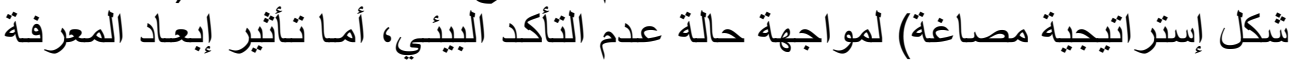

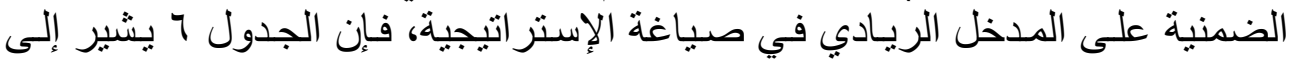
نتائج تحليل الانحدار المتدرج بهذين المتغيرين.

الجدول المبر

نتائج تحليل الاتحار المتدرج لتأثير المعرفة الضمنية في المدخل الريادي لصياغة الإستراتيجية الفئية

\begin{tabular}{|c|c|c|c|c|}
\hline d.f & F المحسوبة & $\mathbf{R}^{2}$ & B & المعرفة الضمنية \\
\hline$(1,35)$ & 73.83 & 0.678 & 0.824 & التفكير \\
\hline$(2,34)$ & 66.74 & 0.797 & $0.674,1.403$ & التفكير+ الحلس \\
\hline
\end{tabular}

$\mathrm{N}=37$

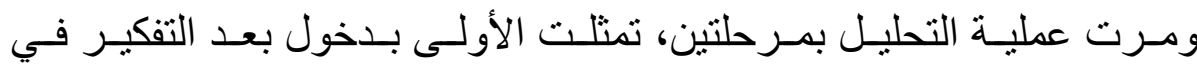

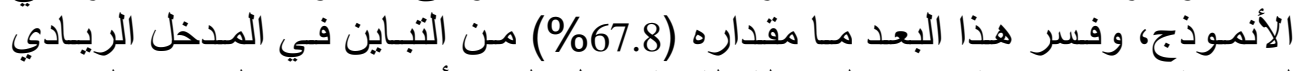

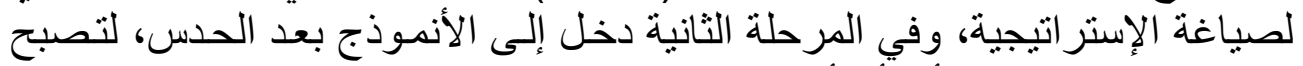

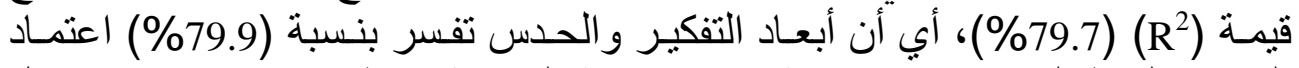

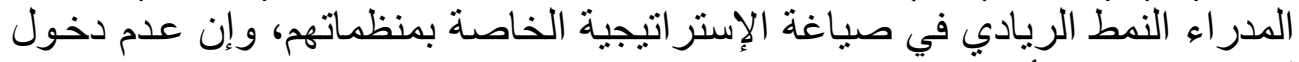

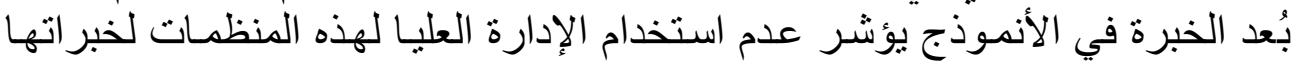

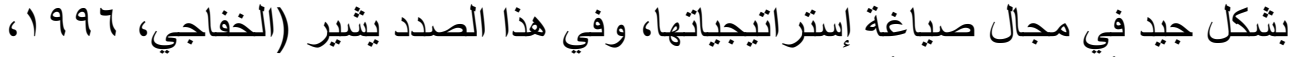

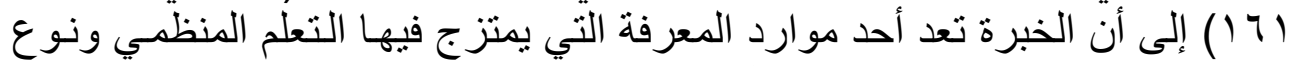

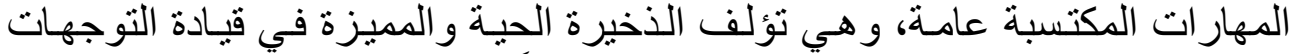

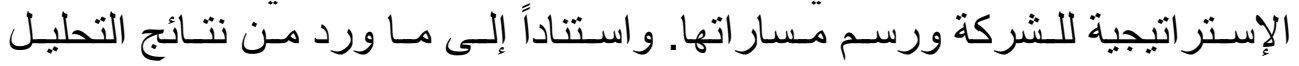
الإحصائي فيمكن القول إن البحث يقبل الفرضية الثانية. 


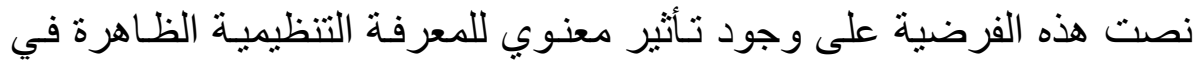

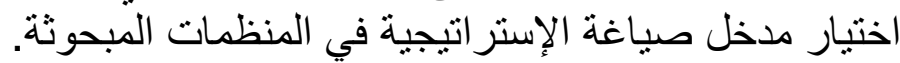

لاختبار هذه الفرضية ستجرى عملية التحليل للمعرفة الظـاهرة مـع كل مدخل

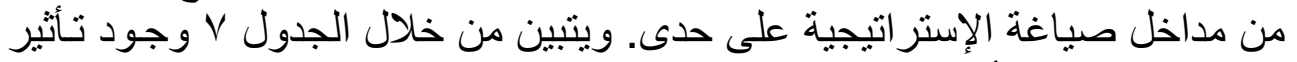

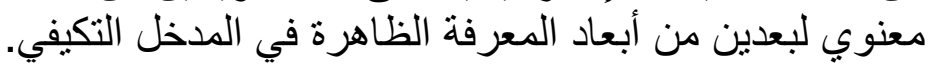

\section{الجدول}

\begin{tabular}{|c|c|c|c|c|}
\hline d.f & F المحسوبة & $\mathbf{R}^{2}$ & B & 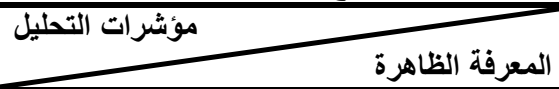 \\
\hline$(1,35)$ & 78.97 & 0.693 & 0.832 & معرفة المنافسبن \\
\hline$(2,34)$ & 104.93 & 0.861 & $1.245,1.911$ & معرفة المنافسين + معرفة السوق \\
\hline
\end{tabular}

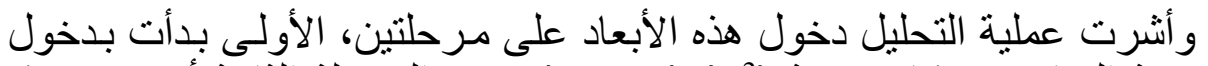

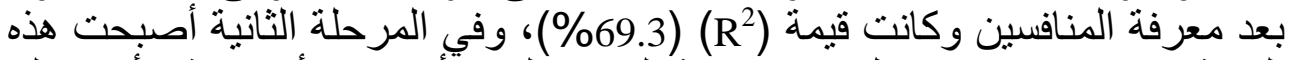

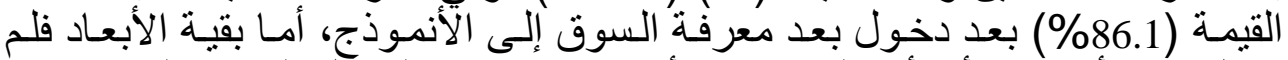

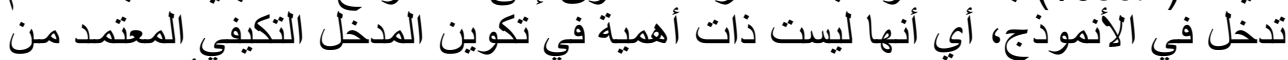

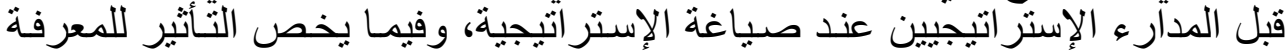

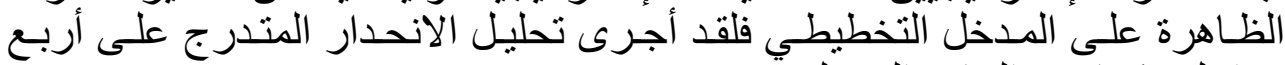

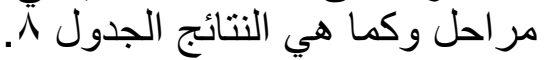

\section{الجدول}

نتائج تحليل الانحدار المتدرج لتأثير المعرفة الظاهرة في المدخل التخطيطي

\begin{tabular}{|c|c|c|c|c|}
\hline d.f & F المحسوبة & $\mathbf{R}^{2}$ & $\mathbf{B}$ & مؤشرات التحليل \\
\hline$(1,35)$ & 17.02 & 0.327 & 0.572 & معرفة الاتصالات \\
\hline$(2,34)$ & 23.66 & 0.582 & $844,1.249$ & معرفة الاتصالات + معرفة المنافسين \\
\hline$(3.33)$ & 20.70 & 0.653 & $\begin{array}{l}0.996 .1 .631 \\
1.043\end{array}$ & المعرفة الاتقنية \\
\hline$(4,32)$ & 18.06 & 0.693 & $\begin{array}{l}1.046,1.045 \\
, 2.228,0.510\end{array}$ & المعرفة التقنية + معرفة + معرفة السوفة المنافسين + \\
\hline
\end{tabular}

$\mathrm{N}=37$

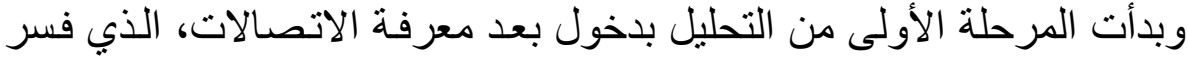

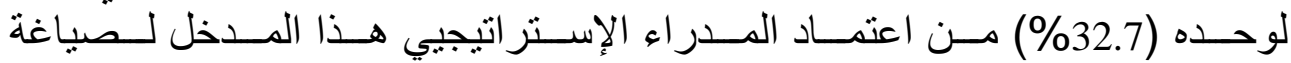

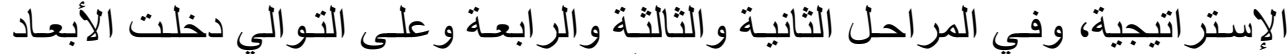

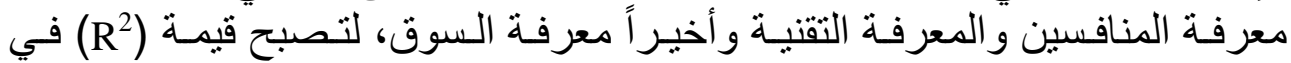

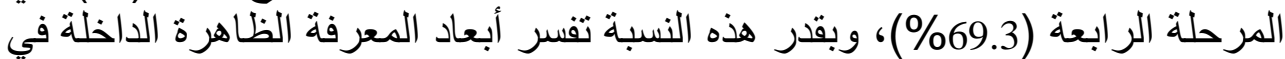

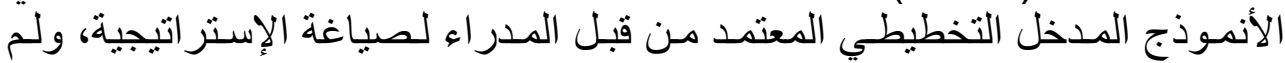




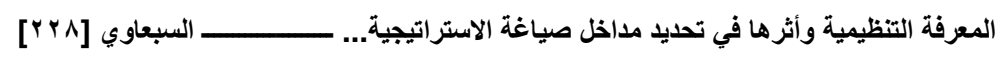

تدخل في هذا النموذج أبعاد المعرفة حول الزبون و المعرفة حول الموردين، و هذا مـا

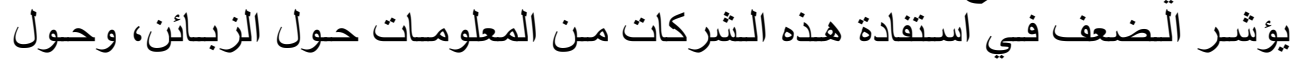
الموردين الذين تتعامل معهم في مجال صياغة إستر اتيجياتها.

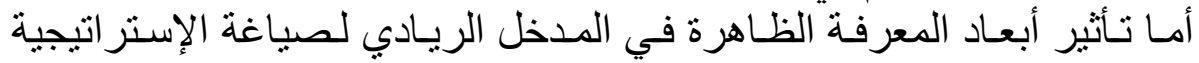
فنتائجه واضحة في الجدول 9.

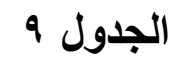

نتائج تحليل الانحدار المتدرج لتأثير المعرفة الظاهرة في المدخل الريادي

\begin{tabular}{|c|c|c|c|c|}
\hline d.f & F & $\mathbf{R}^{2}$ & B & مؤشرات التحليل \\
\hline$(1,35)$ & 211.81 & 0.858 & 0.962 & المعرفة التقتية \\
\hline$(2,34)$ & 151.78 & 0.899 & $0.373,0.613$ & المعرفة التقتية + المعرفة بالمنافسين \\
\hline$(3.33)$ & 161.02 & 0.936 & $547,719,0.799$ & المعرفة بالموردينة + التقتيـة + المعرفـة بالمنافـسين + \\
\hline$(4,32)$ & 159.04 & 0.952 & $\begin{array}{c}0.607,0.799 \\
0.571,0.518\end{array}$ & 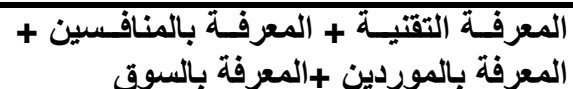 \\
\hline
\end{tabular}

$\mathrm{N}=37$

و تثنير نتائج التحليل إلى التأثير المعنوي لأربعة من أبعاد المعرفة الظاهرة في الإدي

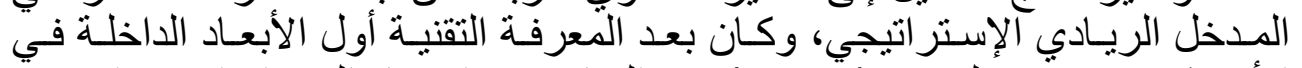

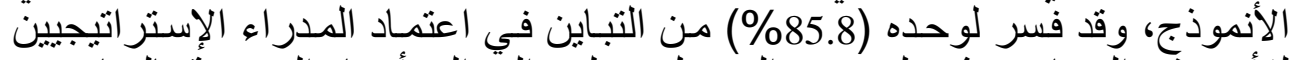

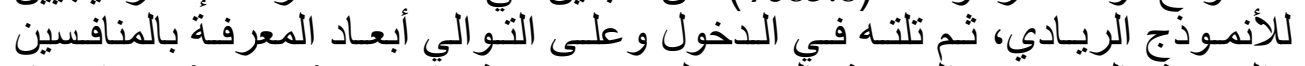

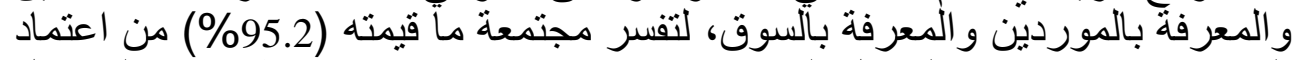

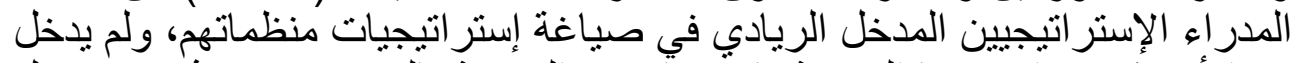

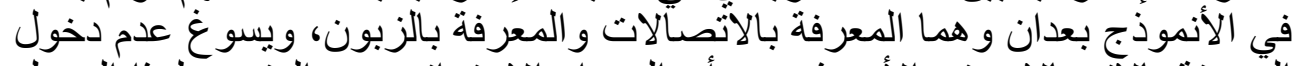

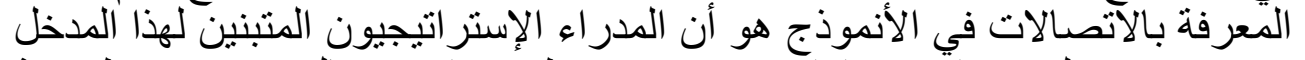

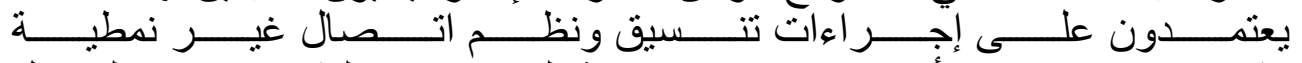

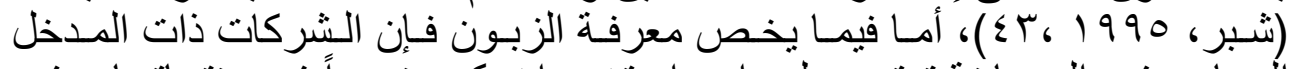

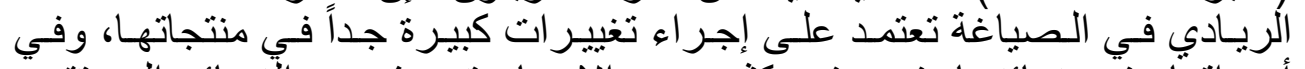

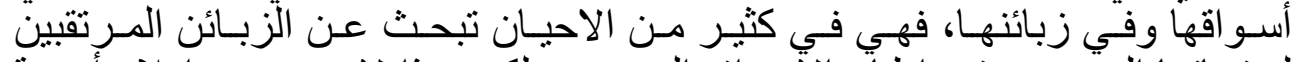

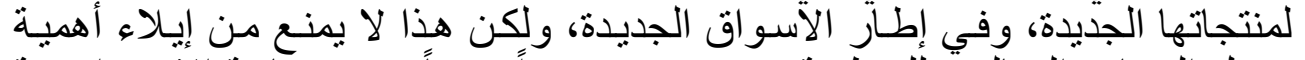

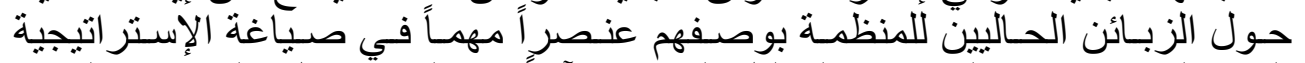

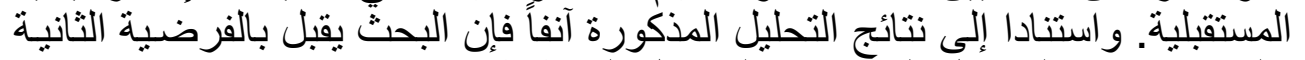

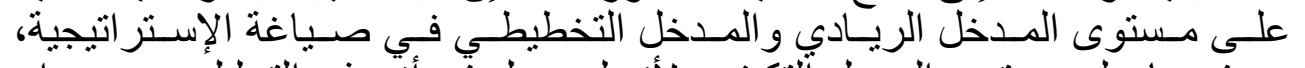

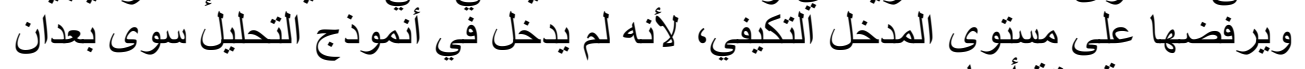

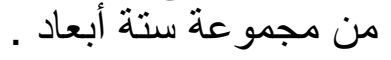

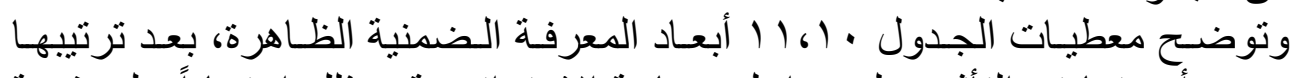

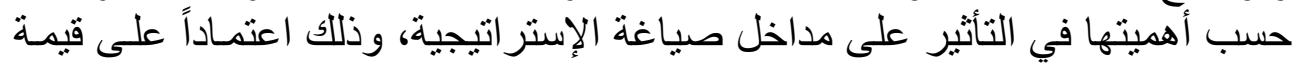
بيتا (Beta). 


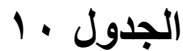

أبعاد المعرفة الضمنية مرتبة حسب أهميتها في التأثير على مداخل صياغة

الإستراتيجية الهمينة

\begin{tabular}{|c|c|c|c|c|}
\hline التفكير & المهارة & الخبرة & الحدس & مدخل الصياغة \\
\hline$r$ & $x$ & 1 & ${ }^{*} x$ & التكيفي \\
\hline$r$ & $x$ & 1 & $x$ & التخطيطي \\
\hline$T$ & $x$ & $x$ & $r$ & الريادي \\
\hline
\end{tabular}

*تشير إلى الأبعاد التي لم تدخل في نموذج تحليل الانحدار .

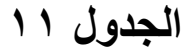

أبعاد المعرفة الظاهرة مرتبة حسب أهميتها في التأثير على مداخل صياغة الإستراتيجية

\begin{tabular}{|c|c|c|c|c|c|c|}
\hline المنافسينة & الموردين & التقتية & الاتصالات & الزبون & السوق & مدخل الصياغة المعرفة الظاهرة \\
\hline 1 & $x$ & $x$ & $x$ & ${ }^{*} x$ & $r$ & التكيفي \\
\hline 1 & $x$ & $r$ & $\varepsilon$ & $x$ & r & التخطيطي \\
\hline$\varepsilon$ & $T$ & $\Gamma$ & $x$ & $x$ & $r$ & الريادي \\
\hline
\end{tabular}

\section{الاستتناجات والتوصيات}

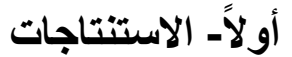

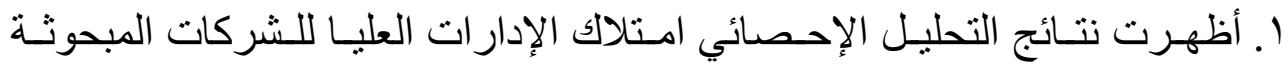

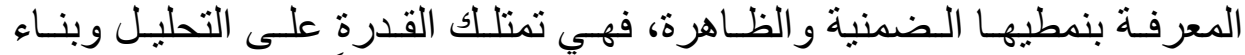

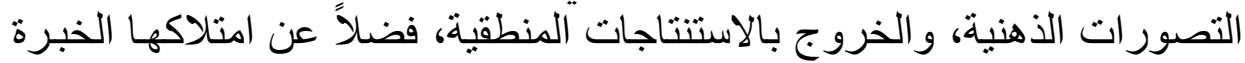

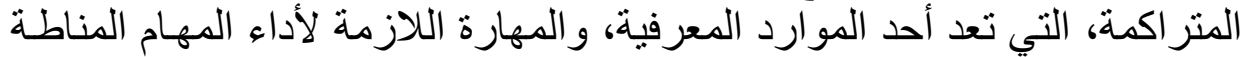

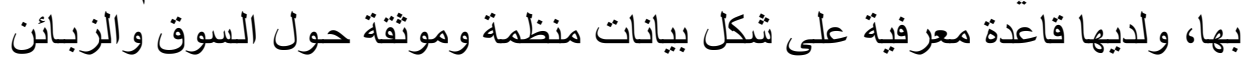

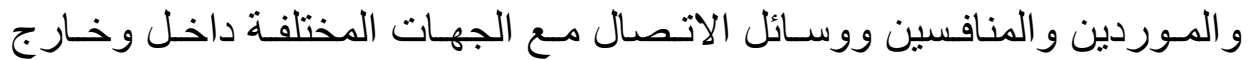

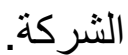
ץ. بينـت نتـائج التحليـل اعتمـاد المـداخل الثلاثـة (التكيفي، و التخطيطي، و الريـادي)

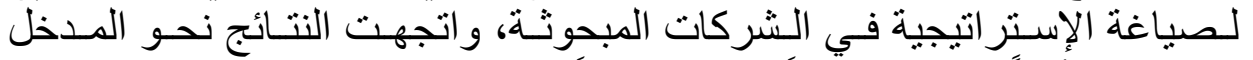

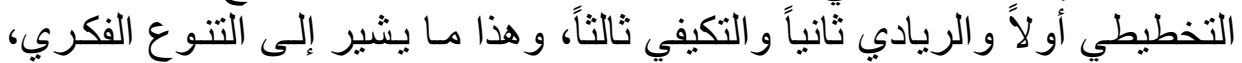

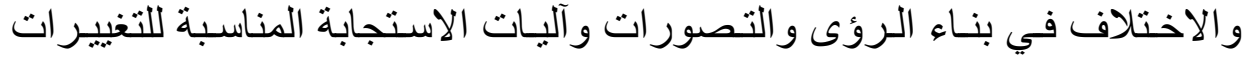

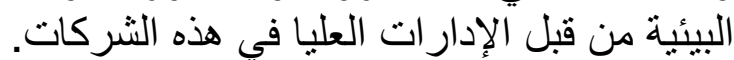

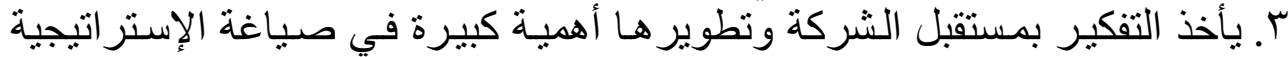

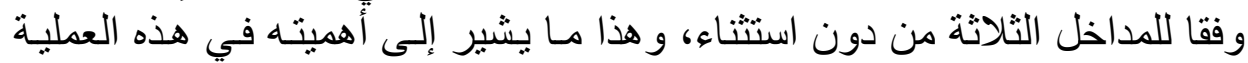
بغض النظر عن طبيعـة التوجـه الإسـتر اتيجي لهذه الشركات أو فلسفة قياداتها 


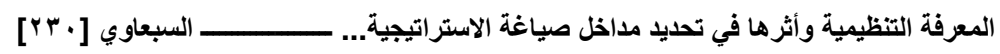

ع. أثرت نتائج التحليل ضعف قدرة المدر اء الإستر اتيجيين في المنظمـات المبحوثة

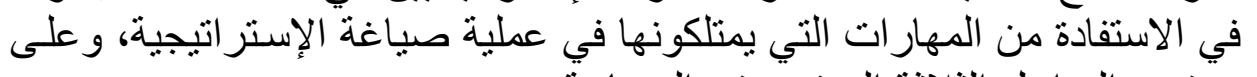
مستوى المداخل الثلاثة المعتمدة في الصيار الصياغة.

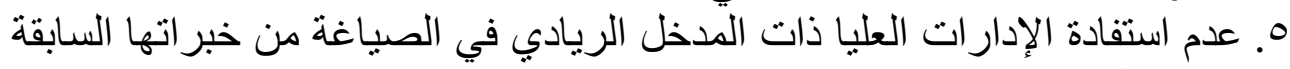

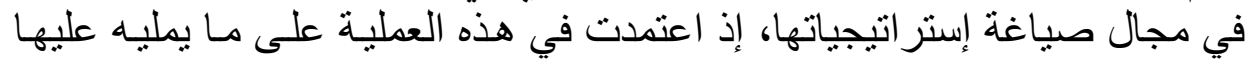
الحدس، والتفكير في مستقبل الثركة.

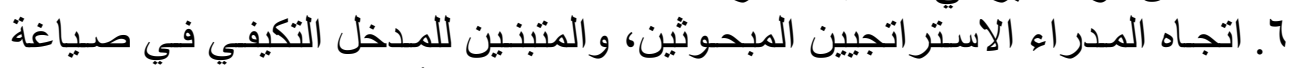

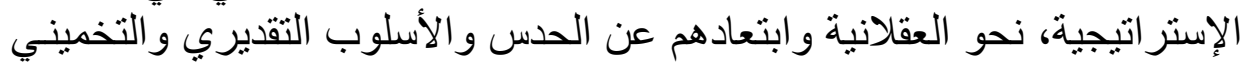

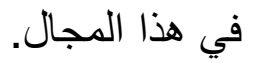

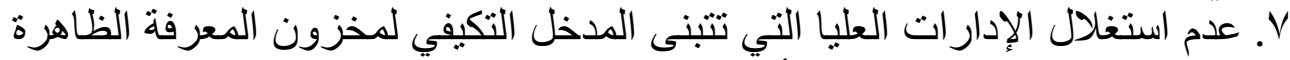

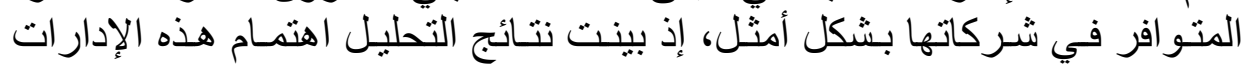

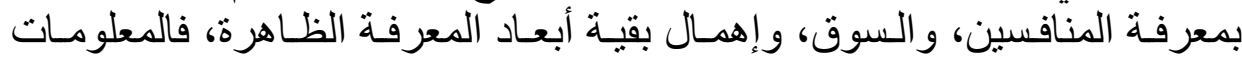

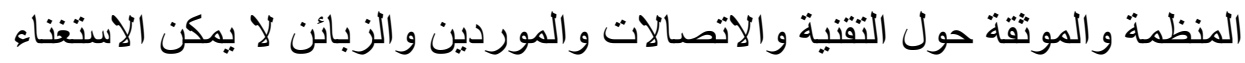

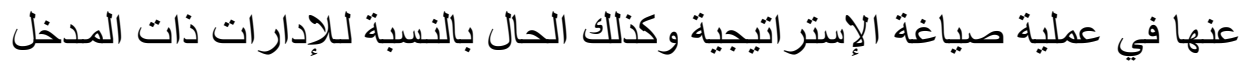

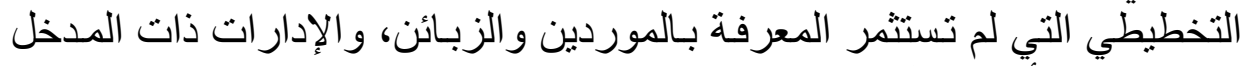

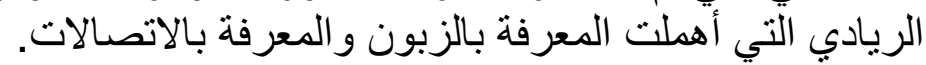

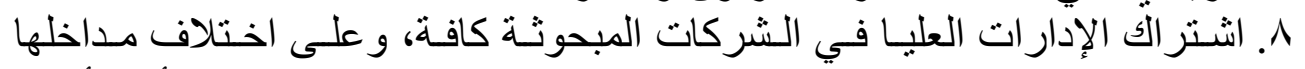

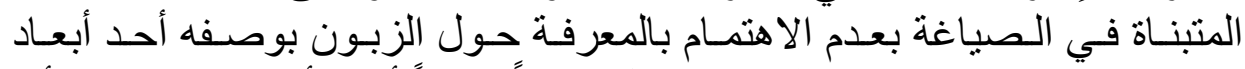

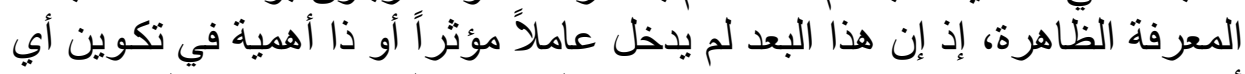

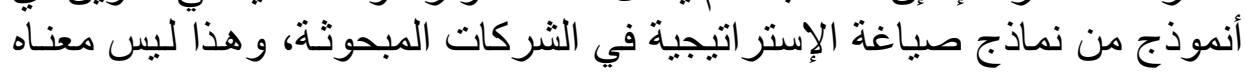

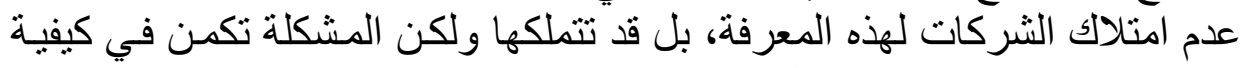
استثمار ها وتسخير ها في مجال صياغة لهذة الإستر اتيجية.

\section{ثانياً. التوصيات}

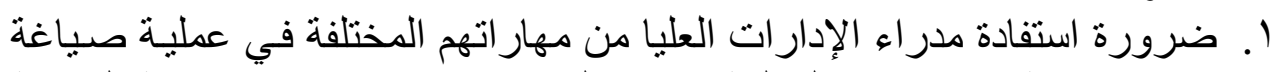

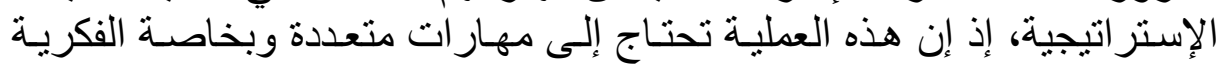
منها.

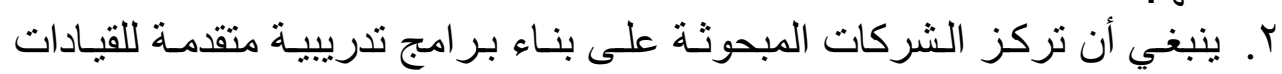

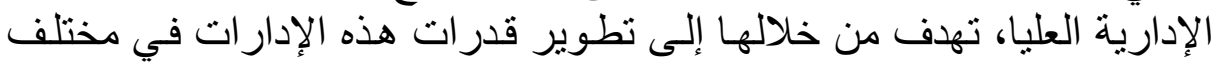

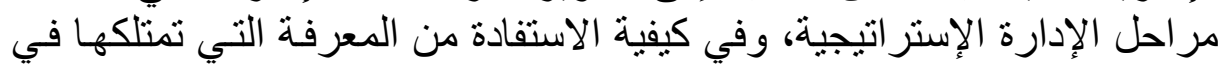
هذه المر احل. مل الادل

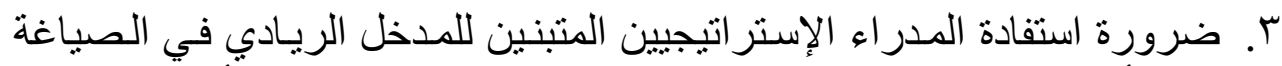

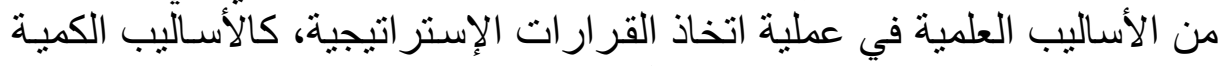

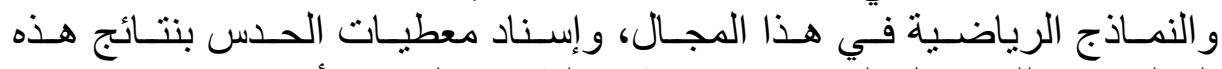

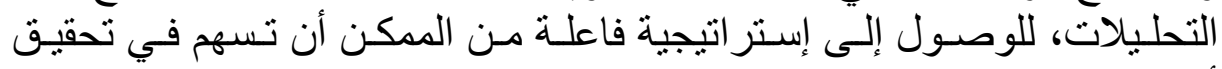

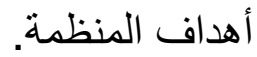


ع. من الواجب على الشركات المبحوثة أن تعمل على بنـاء قاعدة معرفبـة مركبـة

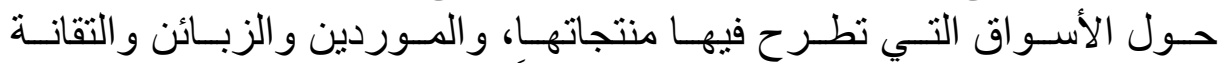

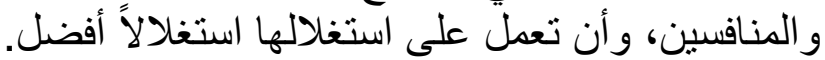

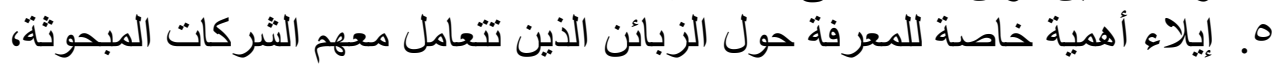

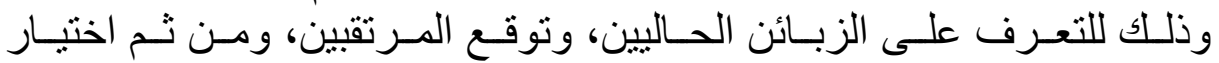

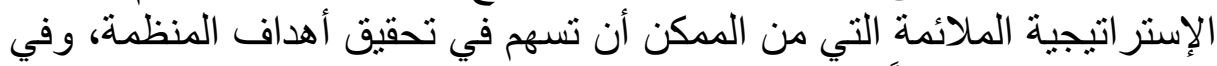

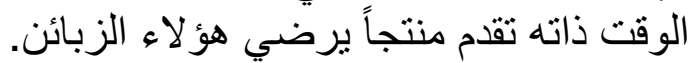

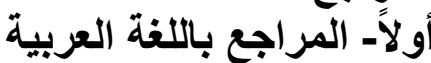

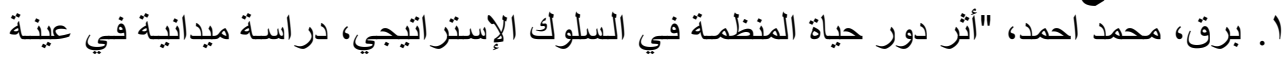

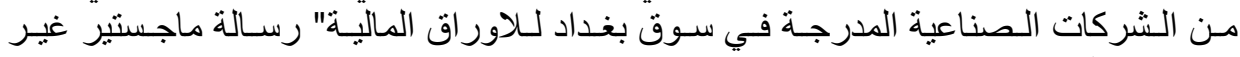

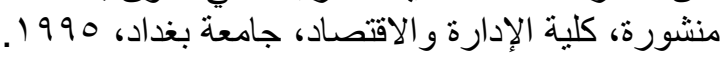

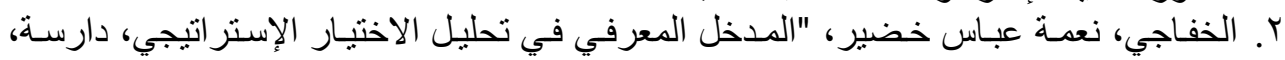

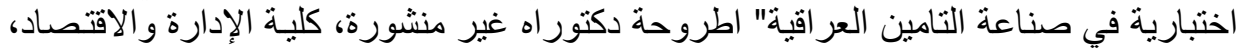

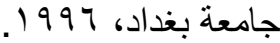

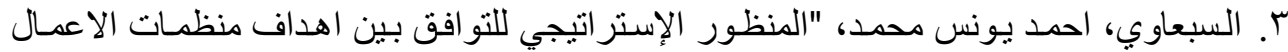

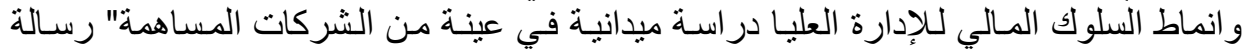

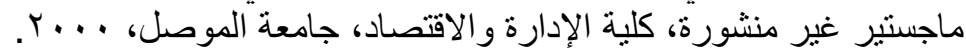

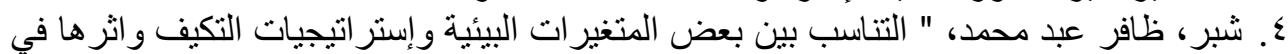

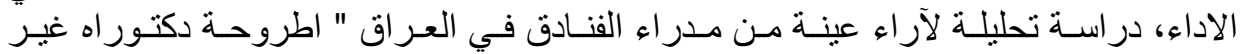

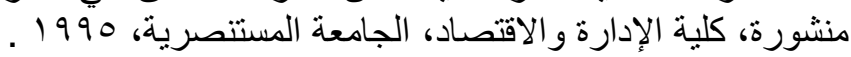

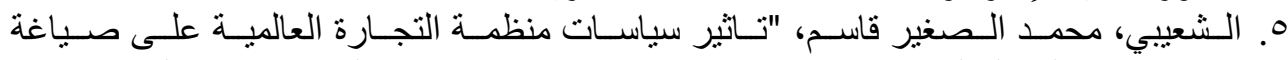

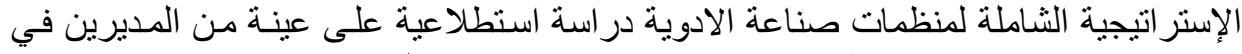

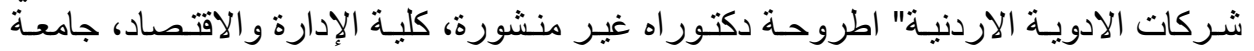

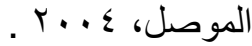

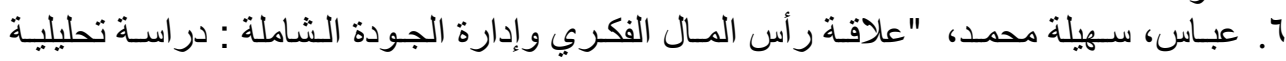

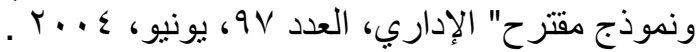

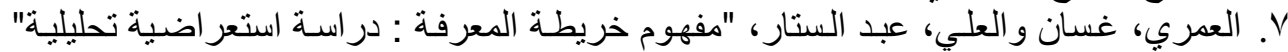

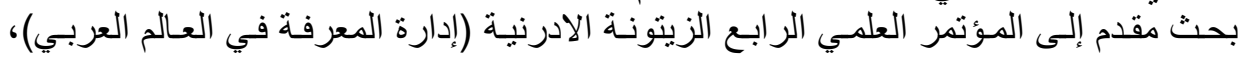
r...

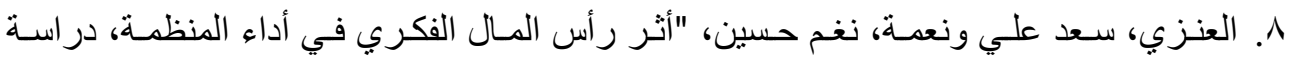

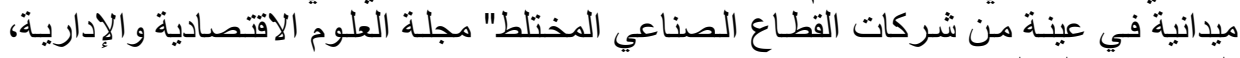

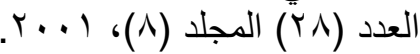

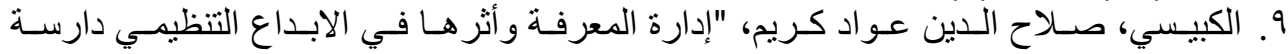

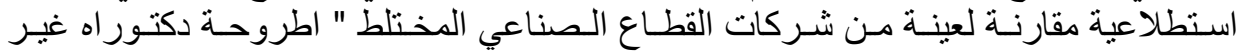

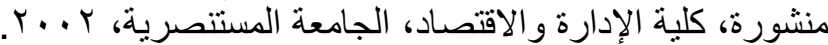

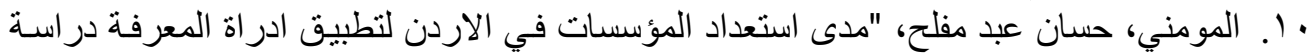

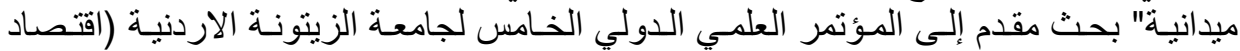

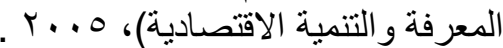




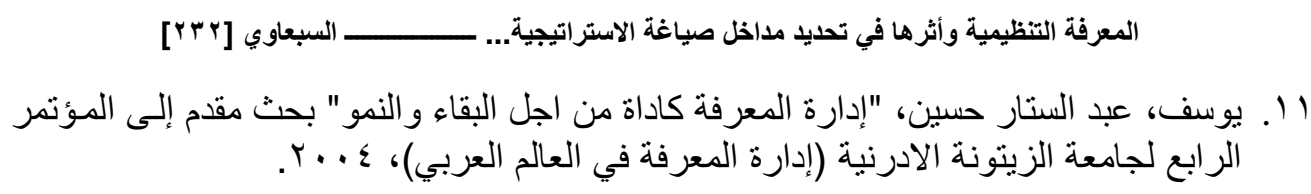

\section{تانياً-المراجع باللغة الاجنبية}

1. Boseman, Gleen \& Phatak, Arvind, "Strategic Management Text And Cases " $2^{\text {nd }}$, Ed ,John Wiley And Sons, Newyork, U.S.A, 1989.

2. Daft. Richard, "Organization: Theory And Design" South Western College Publishing, U.S.A, 2001.

3. Grenz, Sj, "A Primeron Postmodernism" Grand Rapids, Wmb Eerdmans, Publishing Co, 1996.

4. Lynch, Richard, "Corporte Strategy" $2^{\text {nd }}$, Ed, Prentice - Hall, Person Education, Limited, London, 2000.

5. Mintzberg, Henry, "Strategy - Making In Three Modes" Californnia Management Review, Vol. 16 No. 2, Winter, 1973.

6. Quinn, James, Brain, Mintzberg Henry \& Hames, M. Robert "The Strategy Process, Concepts, Contexts And Case "Prentice., Hall, U.S.A, 1988.

7. Struwig, F.W, \& Smith, E.E, "The Relationship Between Organizational Culture And Strategy Formulation In South African Firms South African Business Management, 33. (1), 2002

8. Wheelen, L. Tthomas \& Hunger J. David "Struategic Management And Business Policy" Fifth Edition, Addisno - Wesley Publishing Company, U.S.A, 1995.

1- Baker, A. Kathryn and Badamshina, M. Ghuzal 2002 "Knowledge Management"www.wern-neywork/resources/benchmark/05-Knowledge management .Pdf .

2- Jinxi, wu \& Gisheng, Liu 2001 "Knowledge chain management: Emerging Models practices from the field" paper presented to the international manufacturing network symposium, www.mmd,eng.cam,ac.uk/cim/imnet/symposium 2001 / papers.

3- Maasdorp, chiristiaan 2001 "Bridging individual and organization knowledge: the appeal to tacit knowledge in knowledge, Management theory " Paperpresnted in ISMICK*.

4- Skynme, J. David 2002 "knowledge Management: Approaches and policies" $\quad$ www.providersede.com $/$ docs $/ \mathrm{km}$-article $/ \mathrm{km}$-Approaches

*International symposium the management industrial and corporate knowledge. 